\title{
Safe and effective two-in-one replicon-and-VLP minispike vaccine for COVID-19
}

Alexandru A. Hennrich ${ }^{1}$, Dominic H. Banda ${ }^{1}$, Martina Oberhuber ${ }^{1}$, Anika Schopf ${ }^{1}$, Verena Pfaffinger ${ }^{1}$, Kevin Wittwer ${ }^{2}$, Bevan Sawatsky ${ }^{2}$, Christiane Riedel ${ }^{3}$, Christian K. Pfaller ${ }^{2 *}$, and Karl-Klaus Conzelmann ${ }^{1 *}$

${ }^{1}$ Max von Pettenkofer Institute Virology, and Gene Center, LMU Munich, Munich, Germany

${ }^{2}$ Department of Veterinary Medicine, Paul Ehrlich Institute, 63225 Langen, Germany

${ }^{3}$ Institute of Virology, Department of Pathobiology, University of Veterinary Medicine Vienna, Vienna, Austria

correspondence: conzelmann@genzentrum.Imu.de or christian.pfaller@PEl.de 


\section{Highlights}

- SARS-CoV-2 S RBD antigen is preferred over entire $S$ to preclude potential disease enhancing antibodies

- construction of a chimeric rhabdovirus minispike protein presenting RBD in native conformation

- construction of single round VSV and rabies virus replicon vaccines

- presentation of minispike antigen on cells and on noninfectious VLPS

- strong induction of SARS-CoV-2 neutralizing antibodies by the VSV replicon/VLP system in vaccinated mice

\section{Summary}

The large SARS-CoV-2 spike (S) protein is the main target of current COVID-19 vaccine candidates but can induce non-neutralizing antibodies, which may cause vaccinationinduced complications or enhancement of COVID-19 disease. Besides, encoding of a functional $S$ in replication-competent virus vector vaccines may result in the emergence of viruses with altered or expanded tropism. Here, we have developed a safe single round rhabdovirus replicon vaccine platform for enhanced presentation of the $S$ receptor-binding domain (RBD). Structure-guided design was employed to build a chimeric minispike comprising the globular RBD linked to a transmembrane stem-anchor sequence derived from rabies virus (RABV) glycoprotein (G). Vesicular stomatitis virus (VSV) and RABV replicons encoding the minispike not only allowed expression of the antigen at the cell surface but also incorporation into the envelope of secreted non-infectious particles, thus combining classic vector-driven antigen expression and particulate virus-like particle (VLP) presentation. A single dose of a prototype replicon vaccine, VSVDG-minispike-eGFP (G), stimulated high titers of SARS-CoV-2 neutralizing antibodies in mice, equivalent to those found in COVID-19 patients. Boost immunization with the identical replicon further enhanced neutralizing activity. These results demonstrate that rhabdovirus minispike replicons represent effective and safe alternatives to vaccination approaches using replication-competent viruses and/or the entire $S$ antigen.

\section{Keywords}

virus-like particle, vesicular stomatitis virus, rabies virus, lyssavirus, rhabdovirus, COVID-19, coronavirus, vaccine, spike, RBD 


\section{Introduction}

The current COVID-19 pandemic, caused by SARS-CoV-2, represents an exceptional challenge for our society, economy, and science. Because of the high morbidity and mortality in risk groups and possible long-term multi-organ sequelae in recovered patients regardless of age, strategies to achieve sufficient natural herd immunity are not acceptable. We are therefore witnessing unprecedented efforts and pressure to hastily develop and approve vaccines for application in a huge portion of humanity. Negligence in testing vaccine safety not only puts patients at risk but may also damage public confidence in vaccines and science in general (Thorp, 2020).

Of particular concern for vaccine safety are potentially hazardous delivery vehicles, including newly developed replicating viruses as well as harmful immune responses to inadequate antigens, known as antibody-dependent enhancement (ADE). Of special concern in case of respiratory viruses like SARS-CoV-2 is vaccine-associated enhanced respiratory disease (VAERD) (Cloutier et al., 2020; Jeyanathan et al., 2020; Lee et al., 2020), which happened previously after vaccination with conformationally incorrect viral antigens of respiratory syncytial virus (RSV). Especially, VAERD was associated with high levels of non-neutralizing antibodies. A combination of immune complex deposition, complement activation, and Th2biased immune response led to enhancement of respiratory symptoms (Acosta et al., 2015; Polack et al., 2002; Ruckwardt et al., 2019).

The pandemic SARS-CoV-2 is a novel betacoronavirus (Wu, F. et al., 2020; Zhou et al., 2020; Zhu et al., 2020), closely related to the severe acute respiratory syndrome (SARS) virus (now named SARS-CoV-1) which emerged in 2003 (Drosten et al., 2003; Ksiazek et al., 2003). Previous work on SARS-CoV-1 was highly instructive and provided valuable blueprints for the development of the current COVID-19 vaccine candidates. In particular, Buchholz and colleagues showed that the viral surface spike (S) protein is the only virus protein that stimulates virus neutralizing antibodies (VNAs) (Buchholz et al., 2004; Bukreyev et al., 2004), which are crucial for most vaccine approaches. Accordingly, $\mathrm{S}$ is the main target of current COVID-19 vaccine candidates (WHO, 2020).

The class I transmembrane protein $\mathrm{S}$ is the primary determinant of coronavirus tropism and transmission. The $\mathrm{S}$ precursor protein is processed by cellular proteases into the mature $\mathrm{N}$ terminal S1 and the membrane-bound S2 subunits (Bestle et al., 2020; Hoffmann et al., 2020a; Hoffmann et al., 2020b; Jaimes et al., 2020). S1 contains the receptor-binding domain (RBD) responsible for attachment of the virus to the main cellular receptor, angiotensinconverting enzyme 2 (ACE2) (Lan et al., 2020; Wrapp et al., 2020b). Binding of RBD to the receptor results in profound structural rearrangements required for membrane fusion by the S2 subunit, and release of the viral RNA genome into the cytoplasm. Molecular differences to SARS-CoV-1 S include a higher binding affinity of the RBD to the ACE2 molecule (Lan et al., 2020; Tai et al., 2020; Wrapp et al., 2020b) and the presence of a multibasic cleavage site, probably promoting proteolytic maturation and transport of the protein (Bestle et al., 2020; 
Hoffmann et al., 2020b; Wu, F. et al., 2020). These factors likely contribute to an extended host and organ range and the high contagiousness of SARS-CoV-2 (Kim et al., 2020; Rockx et al., 2020; Shi et al., 2020).

As accumulating data show, COVID-19 patients readily develop high antibody levels directed against the entire $S$ protein, most of which, however, do not neutralize virus infectivity. In contrast, the overwhelming amount of RBD-binding antibodies exhibit neutralizing activity (Brouwer et al., 2020; Cao et al., 2020; Kreer et al., 2020; Premkumar et al., 2020; Zost et al., 2020). Of note, non-neutralizing antibody epitopes of SARS-CoV-1 S were previously found to enhance virus infection (Wang et al., 2016) and it was suggested that anti-S IgG from severely ill COVID-19 patients may promote hyper-inflammatory responses (Hoepel et al., 2020). At this early stage of knowledge, it therefore appears advisable to focus on the RBD immunogen in order to elicit potent neutralizing antibodies and to avoid unnecessary or potentially harmful non-neutralizing $\mathrm{S}$ antibodies.

Recombinant negative strand RNA viruses including rhabdoviruses like the animal pathogen VSV (Lawson et al., 1995) or the zoonotic rabies virus (Schnell et al., 1994) are attractive platforms for experimental vaccines against many emerging and neglected viral diseases, as well as for oncolytic immune therapies (for recent reviews see (Melzer et al., 2017; Zemp et al., 2018)). Rhabdoviruses are bullet shaped, cytoplasmic, and non-integrating RNA viruses encoding a single glycoprotein $(G)$ responsible for receptor attachment and infection of cells. As illustrated before, VSV full-length or $G$ gene-deficient (VSV $\Delta G$ ) vectors expressing functional $S$ of SARS-CoV-1 induced a protective immune response in animal models (Kapadia et al., 2005; Kapadia et al., 2008). As residual pathogenicity of recombinant full length VSV is largely attributed to the glycoprotein G (Roberts et al., 1999), one strategy to attenuate VSV vaccines is the replacement of the $G$ gene by those of heterologous envelope proteins, as exemplified in the recently approved Ebola vaccine VSV-Zebov (Ervebo ${ }^{\circledR}$ ) (Matz et al., 2019). Not surprisingly, G-deficient VSV expressing fully functional SARS-CoV-2 S proteins have now been prepared and proposed as COVID-19 vaccine candidates (Case et al., 2020b; Dieterle et al., 2020; Puelles et al., 2020; Schmidt et al., 2020; Yahalom-Ronen et al., 2020; Zang et al., 2020). Importantly, and in contrast to SARS-CoV-1 S (Fukushi et al., 2006; Kapadia et al., 2005; Kapadia et al., 2008), the authentic SARS-CoV-2 spike protein can readily mediate spread and amplification of $S$ surrogate VSVs in cell culture, organoids, and animals. Moreover, VSVAG-SARS-CoV-2 S rapidly developed mutations in the $\mathrm{S}$ gene to adapt to cell culture conditions and to yield high titer viruses, as well as antibody escape mutations (Case et al., 2020b; Weisblum et al., 2020; Yahalom-Ronen et al., 2020). As attenuation of VSV evidently depends on the glycoprotein used for construction of surrogate viruses and its tropism (van den Pol et al., 2017), extensive preclinical testing is required - as was done in the case of VSV-Zebov (for review see) (Wong, 2018, Matz, 2018) - to inspire confidence in any replicating VSV surrogate virus vaccine.

Here we propose a safe and effective alternative to both replication competent viruses and expression of the full-length SARS-CoV-2 $\mathrm{S}$ antigen to prevent detrimental immune 
responses. Using structure-guided design, we developed a chimeric transmembrane RBD construct, termed "minispike", for enhanced and structurally correct antigen presentation. In the minispike construct, the RBD domain is fused to the transmembrane stem-anchor of the $G$ protein of rabies rhabdovirus (RABV), to allow effective expression as a cellmembrane-bound immunogen. In addition, expression of the minispike from spreadingdeficient (G-deficient) VSV or RABV replicon vectors results in the secretion of non-infectious VLPs decorated with the minispike antigen. In a proof-of-principle experiment, we show that immunization with a single dose of a G-complemented VSV replicon encoding a single copy of the RBD minispike gene (VSVDG-minispike-eGFP) is sufficient to induce high titers of SARSCoV-2 neutralizing antibodies in mice, equivalent to those of COVID-19 patients. As the minispike is compatible with RABV, VSV and probably other rhabdoviruses, which are amenable to envelope switching, the rhabdovirus minispike system offers attractive options for a diversity of prime/boost regimens, including oral immunization with RABV G complemented viruses.

\section{Results}

Design of a rhabdovirus RBD-minispike. The RBD of SARS-CoV-2 spike protein was identified by sequence homology to the SARS-CoV-1 RBD and by functional studies (Lan et al., 2020; Shang et al., 2020; Tai et al., 2020; Yan et al., 2020). Structural analyses revealed a single, discrete, globular-shaped domain, able to switch between "up" and "down" configurations in the context of the pre-fusion form of the S protein, and with the up-conformation needed to engage the ACE2 receptor (Walls et al., 2020; Wrapp et al., 2020b). Based on the structure analysis we selected residues 314-541 (QTSN...KCVNF) to be included in a chimeric transmembrane minispike in which the RBD domain is presented in a natural conformation. In addition, the minispike was designed to be compatible for presentation on the cell membrane as well as for incorporation into the envelope of rhabdovirus-like particles, including VSV and RABV (Fig. 1A).

The amino-terminal signal peptide from human IgG heavy chain (Ig G HV 3-13) was used to promote translation into the endoplasmic reticulum. The carboxy-terminus of the RBD sequence was fused via a short synthetic linker to a transmembrane stem-anchor derived from the glycoprotein of the RABV strain $S A D$, containing the membrane proximal part of the $\mathrm{G}$ ectodomain (stem), the trans-membrane domain, and the cytoplasmic sequence of SAD G (Klingen et al., 2008). The entire construct comprises 367 amino acid residues, including the signal sequence, and two N-glycosylation sites in the RBD part (ITNLCPFGEVFNAT). The SAD $G$ stem was selected because it should allow incorporation into the envelopes of not only RABV, but also of non-RABV rhabdoviruses, such as VSV, which has less stringent sequence requirements for membrane protein incorporation (Mebatsion et al., 1997; Schnell et al., 1998). In the case of VSV, the heterologous stem-anchor was predicted not to critically compete with VSV G incorporation needed during production of infectious single cycle VSV replicon viruses. 
Expression of the minispike construct in HEK293T cells after transfection with plasmidencoded minispike ( $p C R 3-$ minispike) was at first analyzed by Western blot with an anti-SAD C-tail peptide serum (HCA-5) recognizing the RABV-derived anchor sequence (Fig. 1B). Minispike proteins were of the predicted molecular weight range, and deglycosylation experiments with PNGase $\mathrm{F}$ and Endo-H confirmed the presence of complex sugar chains, indicating correct processing and transport through the Golgi apparatus. Expression at the cell surface was further demonstrated by microscopic imaging and positive staining of unfixed live cells with serum from convalescent COVID-19 patients (Fig. 1C).

Construction of minispike-expressing rhabdoviruses. Molecular clones of the Indiana strain of VSV (VSIV) (Lawson et al., 1995) were used as a basis for generation of a series of $\mathrm{G}$ genedeleted VSV replicons (VSV $\Delta G$ ) encoding the minispike (Fig. 2A). The constructs included eGFP reporter viruses and viruses expressing single or multiple copies of the minispike gene inserted either upstream of the L gene, or at the $3^{\prime}$ proximal gene position, which in rhabdoviruses is transcribed most abundantly (Conzelmann, 1998; Flanagan et al., 2000). Recombinant viruses were rescued in HEK293T cells and propagated in cells transfected with VSV G plasmids or in a cell line expressing VSV G (BHK-G43) (Hanika et al., 2005). All VSV $\Delta G$ viruses reached comparable titers in the range of $5 \times 10^{7}$ to $3 \times 10^{8} \mathrm{ffu} / \mathrm{mL}$ after $20-24 \mathrm{~h}$ of infection. G gene-deficient RABV cDNA and replicons were generated on the basis of SAD $\triangle G$ eGFP and grown as described before (Buchholz et al., 1999; Ghanem and Conzelmann, 2016; Ghanem et al., 2012; Mebatsion et al., 1997).

Generation of minispike VLPs and mosaic viruses. As the minispike stem-anchor is derived from the $G$ protein of the RABV SAD strain, we first studied incorporation into virions of the autologous $\mathrm{SAD} \triangle \mathrm{G}$-minispike-mNeonGreen and $\mathrm{SAD} \Delta \mathrm{G}$-bimini-mNeonGreen. Supernatant virions were concentrated through a sucrose cushion by ultracentrifugation and equivalent infectious units were processed for Western blot analysis with a RABV P serum, and anti-SAD G C-tail serum to detect virus-associated minispikes and RABV G (Fig. 2B). Minispike was effectively incorporated into particles both in the absence and in presence of the parental SAD G. In the presence of SAD G less minispike was observed in RABV particles (Fig. 2B), suggesting competition of the homologous SAD G and minispike for incorporation.

To examine incorporation of the "heterologous" minispike into VSV particles, VSV $\Delta$ Gminispike-eGFP stocks were produced in cells transfected with VSV G expression plasmids. For preparation of one stock, VSV G was expressed only 6 hours before VSV $\Delta G$-minispikeeGFP infection occurred, in another preparation VSV G was allowed to accumulate for 24 hours to high levels before infection. Western blot analysis of 1 million infectious units of each with anti-VSV serum revealed effective incorporation along with VSV G (Fig. 2C).

Rhabdovirus $\mathrm{G}$ proteins are incorporated into viral envelopes as $\mathrm{G}$ trimers which is driven by interaction of the C-tails with the internal M-coated viral RNP (Gaudin et al., 1992; Lyles et al., 1992; Zagouras and Rose, 1993), and incorporation supports virus budding (Mebatsion et al., 1996; Schnell et al., 1998). The presence of minispike protein in VSV envelopes could 
thus be due to co-incorporation with VSV G molecules as hetero-trimeric complexes. To determine whether RBD minispike alone supports budding of VSV VLPS, VSVAG-minispikeeGFP stocks were produced in non-complementing cells and processed as above. The absence of VSV G did not prevent incorporation of minispike (Fig. 2B; lane no G), revealing autonomous incorporation and release of non-infectious minispike VSV VLPs from infected, non-complementing cells. Notably, comparable amounts of minispikes were observed in VSV particles irrespective of the presence of G (Fig. 2B). As VSV $\Delta G$ viruses encoding multiple minispike genes did not show improved minispike incorporation or infectious titers, the single copy VSV $\Delta$ G-minispike-eGFP was chosen for further analyses.

The composition of viral envelopes was studied in more detail by cryo-electron tomography (Fig. 3). In the absence of a rhabdovirus G protein, VSV as well as RABV VLPs contained a homogenous surface glycoprotein layer, reflecting autonomous incorporation of the minispike as suggested by the above WB experiments. The size of the globular RBD is about $60 \times 35 \AA$ (Walls et al., 2020; Wrapp et al., 2020b), the minispike construct should thus protrude between 6 and $11 \mathrm{~nm}$ from the membrane. The prefusion form of rhabdovirus $\mathrm{G}$ protein is protruding about $8.5 \mathrm{~nm}$ from the virus membrane, whilst the post-fusion form is protruding about $13 \mathrm{~nm}$ (Albertini et al., 2012). Measuring out RABV virions expressing only $G$ or minispike, or the combination of both, revealed differences in length of the surface protrusions (Fig. 3D). G-covered particles had surface proteins with an average length of 8.15 $\mathrm{nm}(\mathrm{n}=99$, STD $1.07 \mathrm{~nm}$ ) whilst in minispike VLPs this length was reduced to $7.70 \mathrm{~nm}(\mathrm{n}=$ 77, STD 1.35). In the presence of both $G$ and minispike, surface protein protrusions had an average length of $8.45 \mathrm{~nm}(\mathrm{n}=111$, STD $1.47 \mathrm{~nm}$ ). A direct morphological separation between $G$ and minispike was not possible, and no higher order arrangement of the surface glycoproteins was discernible in the tomograms, suggesting random mixing.

Of note, virus preparations produced in the presence of VSV G contained non-viral vesicles with a homogenous, distinct surface protein layer. They likely represent the typical 'Gesicles' or G-nanovesicles formed by the autonomous budding activity of the full length VSV G protein (Mangeot et al., 2011; Rolls et al., 1994). We did not observe similar vesicular structures if RABV G or minispike were expressed. As for the parental RABV G, minispikes thus lack the ability of efficient autonomous budding.

VSV-expressed minispike is recognized by COVID-19 patient sera. To corroborate that VSV replicons express correctly folded, processed and targeted minispike antigens that are recognized by natural antibodies of COVID-19 patients, BHK-21 cells were infected with VSV $\Delta G$-minispike-eGFP (G) and, as a control, with a VSV $\Delta G$ expressing only blue fluorescent protein (VSV $\triangle$ G-tagBFP) and probed with a collection of sera from patients previously tested positive for anti-S IgG in a commercial ELISA. EGFP and BFP fluorescence were used as controls to identify virus-infected cells, while bound patient IgG was detected with an Alexa555-labelled anti-human IgG secondary antibody. As illustrated in Fig. 4A for a representative serum, positive sera brightly stained VSV $\Delta$ G-minispike-eGFP infected unfixed living cells, while no signal was observed with COVID-19 ELISA-negative human control sera 
(Fig. S1). Similarly, RABV replicon-expressed minispike was stained at the cell surface (Fig. 4B). Interestingly, while the patient sera recognized the native minispike protein as expressed by VSV and RABV replicons, they did not react effectively with reduced and SDSdenatured protein in Western blots (Fig. 4C). This indicated that the majority of the available human COVID-19 serum antibodies can only bind native conformational RBD epitopes.

In summary, the results show that the minispike protein expressed from recombinant rhabdoviruses is well recognized by conformational antibodies made in response to natural SARS-CoV-2 infection and that it thus largely mimics the conformational landscape of the natural SARS-CoV-2 S RBD. We reasoned that rhabdovirus replicons encoding chimeric minispike genes therefore represent promising and safe candidates for a COVID-19 vaccine.

\section{A single dose of VSVDG-minispike-eGFP is sufficient for induction of SARS-CoV-2} neutralizing antibodies. To assess the suitability and the sufficiency of a single round VSV $\triangle G$ replicon expressing a single copy of the minispike, we immunized 11-19 weeks-old BALB/C mice with VSV $\Delta$ G-minispike-eGFP (G) by intra muscular (i.m.) administration. As advised by the above results, virus stocks produced under limiting ( $6 \mathrm{hrs}$ ) VSV G complementation were used, to prevent excess formation of $\mathrm{G}$ vesicles. Four mice received a single dose of $1 \times 10^{6}$ infectious particles, while 8 mice received an additional boost with the same virus preparation and dose 28 days following a prime vaccination. As controls, mice immunized the same way with VSV $\Delta$ G-eGFP (VSV G) ( $n=2$ for each condition) or with PBS ( $n=1$ for each condition) were used. The 4 mice receiving only prime vaccination were sacrificed at day 28 , and 4 boosted mice each at day $35(n=4)$ and day $56(n=4)$, to collect serum (Fig. 5A).

Virus neutralization assays were performed with a SARS-CoV-2 virus isolate from Wetzlar, Germany (Bestle et al., 2020). Notably, all 4 mice immunized only once developed detectable titers of SARS-CoV-2 neutralizing antibodies in the range of 1:20-1:40 dilutions (Fig. 5B). Boost vaccination further increased neutralizing titers to 1:160-1:640.

For verification of the notable neutralizing titers in an independent assay, we also produced VSV particles pseudotyped with a functional S protein, VSV-eGFP- $\Delta$ G-GLuc (S $\Delta$ C19). Neutralization assays confirmed the induction of significant levels of S-neutralizing antibodies in mice receiving a single prime vaccination and further enhancement of neutralization activity by boost immunization (Fig. 5C).

In order to directly compare the neutralizing activities of sera from vaccinated mice and from COVID-19 patients, VSV-eGFP- $\triangle$ G-GLuc (S $\triangle$ C19) neutralization assays were employed. For comparison, the previously used human COVID-19 sera were used. Even sera with low ELISA IgG ratios revealed a pronounced neutralizing capacity (Fig. S2). Most intriguingly, the group of mice immunized only once (boxes labeled d 28 in Fig. 6), developed neutralizing antibodies with a capacity almost equal to those of the group of COVID-19 patients (grey boxes), illustrating a powerful induction of humoral immunity by vaccination with the single round VSVAG-minispike-eGFP replicon. Boost immunization further enhanced neutralizing titers to exceed those of patients (Fig. 6). 


\section{Discussion}

There is a dangerous rush of researchers, regulatory agencies, and politicians to win the current COVID-19 vaccine race (Thorp, 2020). While it fortunately appears that SARS-CoV-2 and many of the vaccine candidates in clinical trials can readily stimulate immune responses, (see e.g. (Corbett et al., 2020; Feng et al., 2020; Mulligan et al., 2020; Suthar et al., 2020; $\mathrm{Wu}$, S. et al., 2020)), stringent assessment of antigens and careful selection of delivery vehicles are still necessary before it comes to mass vaccination. Careful selection of antigens is critical for avoiding unfavorable immune reactions and disease enhancement, as in the past experienced with RSV, measles and dengue vaccines (for reviews see (Lee et al., 2020; Ruckwardt et al., 2019)). The use of viral vectors is in general associated with concerns including potential genome integration in case of all DNA vectors, high mutability of some RNA viruses, and the lack of medical control for many replication-competent live vectors. Notably, still many current candidate vaccine vectors seem to involve expression of the fulllength SARS-CoV-2 S protein (WHO, 2020). In some chimeric or surrogate rhabdo- or paramyxoviruses proposed as vaccine candidates, including VSV $\Delta G-S$ or Newcastle disease virus (NDV-S), functional $\mathrm{S}$ is even determining or extending viral spread and tropism, respectively (Case et al., 2020a; Rohaim and Munir, 2020; Sun et al., 2020a; Sun et al., 2020b; Yahalom-Ronen et al., 2020).

Here, we used a structure-guided approach to generate viral replicon vaccines meeting the requirements both in terms of virus safety and antigen harmlessness, as well as in efficacy. Our results illustrate that a small antigen, the RBD of SARS-CoV-2 if presented in the form of the present chimeric minispike protein is sufficient to induce neutralizing antibodies in mice. A single immunization with a safe, spreading-deficient single round biosafety level 1 rhabdovirus replicon was sufficient to elicit neutralizing activity similar to that of COVID-19 patients.

Assessment of antibody responses to different betacoronaviruses has recently underlined that the SARS-CoV-2 RBD is the best target for COVID-19 vaccination. While SARS-CoV-1 and MERS-CoV $S$ proteins encode a number of VNA epitopes located outside of the RBD, the SARS-CoV-2 RBD seems to account for almost all human antibodies with potent neutralization capacity, (Barnes et al., 2020; Brouwer et al., 2020; Cao et al., 2020; Kreer et al., 2020; Zost et al., 2020), with rare exceptions (Chi et al., 2020). Furthermore, presentation of the antigen is key for the success of immunization. While this work was in progress, data on various $\mathrm{S}$ protein constructs became available. While soluble monomeric RBD protein suffered from limited immunogenicity, a tandem repeat single chain construct enhanced immunogenicity (Dai et al., 2020). A soluble trimeric RBD, as applied in the BNT162b1 mRNA vaccine, showed promising immunogenicity in clinical trials, including stimulation of antibodies and T cell responses (Mulligan et al., 2020; Sahin et al., 2020). In addition to trimerization, membrane anchoring seems to further improve immunogenicity, as 
transmembrane anchored full-length $S$ prefusion-stabilized protein was reported to elicit higher VNA levels than corresponding secreted constructs (Corbett et al., 2020).

Here we used a previously applied strategy to present a trimeric transmembrane RBD in the form of a rhabdovirus minispike. The discrete and flexible globular structure of the RBD (Tai et al., 2020; Wrapp et al., 2020b; Yan et al., 2020) called for its combination with a rhabdovirus stem-anchor construct we have previously identified as suitable for presentation of a structurally intact protein domain (dsRED) on the surface of cells and on RABV particles (Klingen et al., 2008). The antigenic properties of the RBD in the context of the minispike remains similar to those in natural $\mathrm{S}$ protein, as initially indicated by binding of COVID-19 patients' IgG to cells expressing the minispike construct (Figs 1, 4). Actually, we were initially astonished by the strong immune fluorescence signals, but in the meantime extensive characterization of natural human and animal monoclonal antibodies has revealed multiple, independent conformational epitopes in the RBD (Baum et al., 2020; Brouwer et al., 2020; Cao et al., 2020; Huo et al., 2020; Kreer et al., 2020; Tian et al., 2020; Wang et al., 2020; Wrapp et al., 2020a; Yuan et al., 2020; Zost et al., 2020). The simultaneous targeting of distinct RBD antigenic sites is of relevance not only for the efficiency of a vaccine but also in the light of potential emergence and spread of SARS-CoV-2 variants resistant against individual antibodies (Baum et al., 2020; Weisblum et al., 2020). Ongoing screening of rat monoclonal antibodies generated in response to VSVDG-minispike-eGFP will reveal whether the chimeric minispike presents a full complement of natural RBD epitopes.

The minispike is presented copiously at the cell surface membrane, and in addition is incorporated into rhabdovirus VLPs, or mosaic viruses in the presence of G, as confirmed by immune fluorescence of cells, immune blot, and cryo-EM of virions. Reflecting the previous observations, that RABV and VSV G protein trimers are rather instable (Sissoeff et al., 2005; Zagouras and Rose, 1993), we could not immediately demonstrate a trimeric form of the minispike on the cell surface. In the context of viral envelopes, however, in which the internal RNP and matrix protein layers determine organization (Ge et al., 2010; Lyles et al., 1992; Mebatsion et al., 1996; Mebatsion et al., 1999; Riedel et al., 2019), trimeric G spikes form highly ordered paracrystalline arrays. It was suggested that the repetitive arrangement of $G$ epitopes as observed in VSV is responsible for stimulating a very strong antibody response, by crosslinking of $B$ cells via receptors, and possibly by contribution of $T$ cellindependent mechanisms (Bachmann et al., 1995; Szomolanyi-Tsuda and Welsh, 1998). VLPs in general are potent immunogens, and some VLPs may be transported to local lymph nodes to promote immune responses (Roldão et al., 2010; Roy and Noad, 2009). We assume that the non-infectious minispike VLPs as generated here are synergizing with cell membrane expressed antigen, although quantification of their exact contribution to the overall immune response will require further experimentation with purified VLPS.

The excellent immunogenicity of the minispike in the context of a single-round, G-deficient VSV vaccine was illustrated by induction of high levels of SARS-CoV-2 neutralizing antibodies 
in mice. Notably, VNA activities equaling those of COVID-19 patients were detectable in animals receiving only a single i.m. dose of vaccine, and boost vaccination with the identical virus in the same hind leg further boosted VNA activity to levels superior to those of COVID19 patients. VSV infection is known to induce a strong Th1 biased antiviral and anticancer immune response (Bongiorno et al., 2017; De Giovanni et al., 2020). This holds also true for VSV $\Delta$ G-minispike-eGFP vaccination, as indicated by preliminary results from rats. More than $95 \%$ of $S$ positive IgG hybridomas produced immune globulins of the IgG2 subclass, while IgG1 was only sporadically observed, thus reflecting strong Th1 immune response. A favorable humoral and cellular immune response bias as observed for BNT162b1, an adjuvanted, secreted trimeric RBD mRNA vaccine (Mulligan et al., 2020), is obtained with VSV $\Delta$ G-minispike-eGFP in the absence of exogenous adjuvants.

While the chimeric minispike construct as described here appears to be immediately suitable in any genetic vaccine approach, including the auspicious mRNA platforms (Mulligan et al., 2020; Walsh et al., 2020), its full potential is accomplished in the context of the highly flexible rhabdovirus vector system, which integrates antiviral innate and adaptive immune responses. As shown here, the VSVDG replicon complemented with little VSV G protein to mediate infection of muscle cells is highly effective in SARS-CoV-2 S RBD antigen expression after i.m. application, and intraperitoneal (i.p.) administration is supposed to be similarly effective (Kapadia et al., 2008). Boost immunizations with the same virus led to strong increase in VNA titers, revealing a moderate non-sterilizing antibody response to the VSV G protein. While results for RABV $\triangle$ G-based minispike vaccines are not yet available, both VSV and RABV are amenable to envelope switching, such that pseudotyping of rhabdovirus minispike replicons with a variety of heterologous $G$ proteins is feasible, in case repeated boosts should be necessary. RABV $\triangle \mathrm{G}$ or VSV $\triangle \mathrm{G}$ minispike vectors complemented with the $\mathrm{G}$ protein of widely used RABV strains like SAD in addition offer the intriguing possibility of oral immunization, in the context of prime or boost regiments.

\section{Methods}

Cells. HEK293T and VeroE6 (ATCC) were maintained in DMEM Medium (GIBCO) containing $10 \%$ fetal bovine serum, $1 \%$ L-Glutamine (GIBCO) and 0,5\% Pen. Strep (GIBCO). BHK-G43 cells (Hanika et al., 2005), kindly provided by Georg Herrler, and BSR-MG-on cells (Finke et al., 2003) were maintained in GMEM media containing $10 \%$ fetal bovine serum, $0,5 \%$ Pen/Strep, 1\% MEMs/NEAAs and 19,5mL tryptose phosphate broth (Thermo Fisher). VSV G expression in BHK-G43 cells was induced by adding $10^{-9}$ molar mifepristone 3 hours prior to infection, and RABV G in MG-on cells by adding $1 \mu \mathrm{M}$ doxycycline. All cells were maintained at $37^{\circ} \mathrm{C}$ under $5 \% \mathrm{CO}_{2}$.

Construction of cDNAs. NCBI Reference Sequence NC_045512.2 of nCoV, Wuhan isolate 1, was used to synthesize human codon optimized cDNAs encoding full length HA-tagged spike (S-HA), and minispike (Thermo Fisher GeneArt). The minispike construct comprised $S$ residues 314-541, QTSN...KCVNF fused via a GSG linker to the stem-anchor construct of SAD 
G described in (Klingen et al., 2008). Constructs were inserted into pCR3 for analysis of protein expression in transfected HEK293T cells and for further subcloning in RABV and VSV replicon cDNA. For production of VSVAG(S) pseudotype viruses, we used an S-HA derived construct, pCG-S- $\triangle$ C19, kindly provided by Christian Buchholz, PEI. Plasmids for expression of wt S Protein and S variants included pCG-nCoV-S, pCG-nCoV-S $\Delta C$, and pCG-nCoV-S-V5, kindly provided by Konstantin Sparrer and Caterina Prelli Bozzo.

Construction and rescue of recombinant rhabdoviruses. To obtain recombinant replicationcompetent VSVs, an infectious plasmid clone of VSIV, pVSV-eGFP (Lawson et al., 1995) (kindly provided by Jack Rose) was used to insert minispike cistrons or exchange the eGFP cassette with single or multiple copies of the minispike cistron. To yield G gene-deleted VSV replicons encoding RBD minispike the VSV G gene was replaced with minispike cassettes. To generate VSV-eGFP- $\Delta$ G-GLuc, VSVeGFP $\Delta$ G (addgene \#31842, kindly provided by C. Cepko) was used to insert a cistron encoding Gaussia Luciferase (GLuc) between $G$ and $L$ genes. pVSVdG-4BFP2 was obtained from I. Wickersham via addgene, (\#64101). Virus rescue was performed in HEK293T cells transfected with the viral cDNA plasmids directing T7 RNA polymerase-driven transcription of viral antigenome (+) RNAs from a T7 promoter along with expression plasmids encoding T7 RNA polymerase and VSV helper proteins $N, P$, and L (pCAG-T7, -N, -P, -L; addgene \#59926, \#64087, \#64088, \#64085, respectively, all provided by I. Wickersham). Virus stocks of VSVAG constructs were produced in HEK293T cells transfected with pCAGGs-VSV G, or BHK-G43 and concentrated by ultracentrifugation over a $20 \%$ sucrose cushion in a SW32 rotor at $24,000 \mathrm{rpm}$ and $4^{\circ} \mathrm{C}$ for $2 \mathrm{~h}$.

Recombinant cDNAs of RABV $\triangle \mathrm{G}$ expressing minispike and mNeonGreen were generated by replacement of the eGFP cassette of pHH_SAD $\Delta$ G-eGFP_SC with two transcription units and rescued into virus in cells providing RABV N, P, L, and T7RNA polymerase as described before (Buchholz et al., 1999; Ghanem and Conzelmann, 2016; Ghanem et al., 2012). RABV $\Delta G$ replicons were propagated in MG-on cells providing SAD G (Finke et al., 2003).

Western blots. Laemmli SDS-PAGE in $6 \%$ stacking and $10 \%$ separating Bis-Tris gels and Western blot analysis on semi-dry-blotted PVDF membranes was done as previously described (Schuhmann et al., 2011). Briefly, membranes were incubated with primary antibodies at $4^{\circ} \mathrm{C}$ overnight, and after three times washing with TBS-T incubated for $2 \mathrm{hrs}$ with horseradish peroxidase-conjugated secondary antibodies at room temperature. BioRAD Clarity Western Enhanced Chemiluminescence (ECL) Substrate kit was used for detection in a Fusion Fx7 imaging system.

Microscopy. For live cell imaging, VeroE6 or HEK293T cells were seeded into poly-D-lysine (Millipore-Sigma)-coated multiwell plates one day prior to infection with VSV replicons at the indicated MOIs or plasmid transfection by lipofection, respectively. Infected cells were incubated overnight at $32^{\circ} \mathrm{C}$. Minispike was detected by incubation with human COVID-19 patient sera or the serum of a healthy donor diluted 1:300 in DMEM fluorobrite for one hour at $37^{\circ} \mathrm{C}$ and subsequent staining with anti-Human IgG $(\mathrm{H}+\mathrm{L})$ AlexaFluor555 (1:2,000 in DMEM 
Fluorobrite, $1 \mathrm{~h}, 37^{\circ} \mathrm{C}$ ) and imaged after washing with DMEM fluorobrite. For fixation and permeabilization, infected or transfected cells were washed once with PBS and treated with $80 \%$ acetone for $20 \mathrm{~min}$ at room temperature. After blocking with $5 \%$ bovine serum albumin (BSA) in PBS for $1 \mathrm{~h}$ at room temperature, and three times washing, cells were incubated with COVID-19 patient sera and HCA-5 rabbit peptide serum in PBS with 1\% BSA over night at $4^{\circ} \mathrm{C}$. The cells were then washed three times with PBS and incubated with anti-Human IgG $(\mathrm{H}+\mathrm{L})$ AlexaFluor488 and anti-Rabbit $\lg \mathrm{G}(\mathrm{H}+\mathrm{L})$ AlexaFluor555 for one hour at room temperature. After 3 washing steps, cells were imaged on a Leica DMi8 microscope equipped with LED405 (blue), GFP (green), TXR (red) and Cy5 (far red) filter cubes.

Cryo-electron microscopy. Concentrated preparations of rhabdovirus pseudotype particles were added to glow discharged Quantifoil 200 mesh 2/1 holy carbon copper grids in the presence of Aurion protein A $10 \mathrm{~nm}$ gold beads. Vitrification was performed either with a manual plunging unit or a FEI Vitrobot. Grids were analyzed in a FEI Glacios or a FEI Talos Arctica operated at $200 \mathrm{kV}$ and bidirectional or dose symmetric tilt series were acquired with a FEI Falcon 2 direct electron detector. Tomograms were subsequently reconstructed with etomo and visualizsed with 3dmod (Kremer et al., 1996).

Animal experiments. Mouse immunization studies were carried out in the animal housing facility of the Paul-Ehrlich-Institute, in compliance with the regulations of German animal protection laws and authorized by the responsible state authority (V54-19c20/15F107/1058). 11-19 weeks old female BALB/C mice received one or two intramuscular injections of $1 \times 10^{6} \mathrm{ffu}$ of either VSV $\Delta$ G-minispike-eGFP (VSV G), or VSV $\Delta \mathrm{G}$ (VSV G) "empty" dissolved in $30 \mu \mathrm{l}$ PBS, or an equal volume of PBS alone, four weeks apart (prime or prime/boost). Mice receiving only a single dose of vaccine were sacrificed on day 28 , mice from the prime/boost group were sacrificed on days 35 or 56 . The mice were anesthetized by intraperitoneal injection of $100 \mathrm{mg} / \mathrm{kg}$ body weight ketamine and $10 \mathrm{mg} / \mathrm{kg}$ body weight xylazine and exsanguinated retroorbitally or by cardiac puncture. Whole blood was collected in Z-gel containing tubes (Sarstedt). Serum was separated by centrifugation at $14,000 \mathrm{~g}$ for $15 \mathrm{~min}$ at room temperature and stored at $-20^{\circ} \mathrm{C}$.

Virus neutralization assays. SARS-CoV-2 neutralizing antibody titers were determined by mixing serial dilutions of serum collected from mice at the indicated time points with $10^{2}$ TCID50 of SARS-CoV-2 (Wetzlar isolate), kindly provided by Eva Friebertshäuser (Bestle et al., 2020). Virus and serum dilutions were incubated at $37^{\circ} \mathrm{C}$ for $20 \mathrm{~min}$ before $50 \mu \mathrm{l}$ of VeroE6 cells were added to each well. After incubation for 3 days at $37^{\circ} \mathrm{C}$, cell monolayers were stained with PBS containing $4 \%$ paraformaldehyde (PFA) and $1 \%$ crystal violet. The neutralizing titer is expressed as the reciprocal of the highest dilution at which no cytopathic effect (CPE) was observed.

Neutralization of VSV (S) pseudotyped viruses were performed as follows: HEK293T cells transfected with pGC-S $\triangle$ C19 (obtained from Christian Buchholz) for one day were infected with VSV G-complemented VSV-eGFP- $\triangle$ G-GLuc at a MOI of 1 . After 3 hrs incubation, excess 
input virus was removed by thorough washing. After incubation for $24 \mathrm{~h}$, supernatant was collected, and $\mathrm{S}$ pseudotype virions concentrated by ultracentrifugation through a sucrose cushion, resuspended in PBS and titrated on VeroE6 cells in the presence of VSV-neutralizing hybridoma supernatant (I1-Hybridoma, ATCC CRL-2700) to block residual input G-containing virus. Briefly, VeroE6 cells were seeded at a density of $1 \times 10^{4}$ cells per well in 96 well-plates, and incubated with $10^{2} \mathrm{ffu}$ of $\mathrm{S}$ pseudotype viruses in the presence of 11 supernatant, and with cell culture medium as a control, or increasing dilutions of mouse or human sera, as indicated, in a total volume of $100 \mu \mathrm{L}$. Infectious units were determined after one-day incubation by manual counting of fluorescent cells in triplicate experiments.

Data representation and statistical analysis. Statistical analyses were performed using GraphPad Prism version 8.4.3. Unless otherwise stated, data are from at least three technical replicates. Statistical significance was calculated using 2-tailed Student t-test or one-way ANOVA; results are indicated in figures $\left(* \mathrm{p}=0.05 ;{ }^{* *} \mathrm{p}<0.01 ; * * * \mathrm{p}<0.001 ; * * * *\right.$ $\mathrm{p}<0.0001 ;{ }^{\text {ns }}$ not significant).

Lead Contact and Materials Availability. Requests for material can be directed to the lead contact, Karl-Klaus Conzelmann (conzelmann@genzentrum.Imu.de). All materials and reagents will be made available upon installment of a material transfer agreement (MTA).

\section{Acknowledgements}

We thank Konstantin Sparrer, Ulm University, for interactions of all sorts, and Yassine Haddad for help in establishing the VSV rescue system. Plasmids were kindly provided by John K. Rose (VSIV cDNAs), lan Wickersham and Conny Cepko (addgene VSV cDNAs), Christian Buchholz (S $\triangle \mathrm{C} 19$ ), Konstantin Sparrer, Caterina Prelli Bozzo, and Stefan Pöhlmann (S, S- $\Delta$ C, S-V5). We thank Georg Herrler for providing BHK-G43 cells, Ralf Bartenschlager for ACE2-expressing cells, and Eva Friebertshäuser and Stephan Becker for the SARS-CoV-2 isolate. Max Münchhoff and Patricia Spaeth kindly provided patient sera. Research in the authors' labs is supported by the Deutsche Forschungsgemeinschaft (DFG, German Research Foundation) - Project-ID 369799452 - TRR237 A12", - Project-ID 118803580 - SFB 870 Z1", and Co260/5, and by FöFoLe (Förderprogramm für Forschung und Lehre) of the Medical Faculty of the LMU Munich (FöFoLe M 09/2017). CKP is supported by the DFG Collaborative Research Center 1021 (project number 197785619/B09) and by intramural funding of the German Federal Ministry of Health (BMG), and BS by the German Center for Infection Research (DZIF), project number HZI2016Z9. Cryo-electron microscopy was performed at the Electron Microscopy Facility at Vienna BioCenter (VBC) Core Facilities (VBCF), Austria, and at the CEITEC. The help of Thomas Heuser and Jiři Nováček with the cryo-EM data collection is greatly appreciated. CR was supported by CIISB research infrastructure project LM2018127 and project number CIISB \#200084C funded by MEYS. We thank Konstantin Sparrer and Norbert Tautz for expert review of the manuscript. 


\section{Author contributions}

$\mathrm{AAH}, \mathrm{KKC}$, and CKP contributed to the concept of the study, AAH designed and cloned viruses. CR performed cryo-EM analyses, KW, BS and CKP performed mouse experiments and BS performed SARS-CoV-2 virus neutralization assays. DHB, MO, AS, and VP produced S pseudotype viruses and performed neutralization assays, DHB conducted statistical analysis. All authors contributed to writing and editing of the manuscript and have agreed to the submitted version.

\section{Declaration of interests}

$\mathrm{AAH}$ and $\mathrm{KKC}$ are listed as inventors on a rhabdovirus minispike patent application.

\section{References}

Acosta, P.L., Caballero, M.T., and Polack, F.P. (2015). Brief History and Characterization of Enhanced Respiratory Syncytial Virus Disease. Clin Vaccine Immunol. 23(3), 189-195. DOI: 10.1128/CVI.0060915.

Albertini, A.A., Mérigoux, C., Libersou, S., Madiona, K., Bressanelli, S., Roche, S., Lepault, J., Melki, R., Vachette, P., and Gaudin, Y. (2012). Characterization of Monomeric Intermediates during VSV Glycoprotein Structural Transition. PLOS Pathogens. 8(2), e1002556. DOI:

10.1371/journal.ppat.1002556.

Bachmann, M.F., Hengartner, H., and Zinkernagel, R.M. (1995). T helper cell-independent neutralizing $B$ cell response against vesicular stomatitis virus: role of antigen patterns in $B$ cell induction? European journal of immunology. 25(12), 3445-3451. Published online 1995/12/01 DOI: 10.1002/eji.1830251236.

Barnes, C.O., Jette, C.A., Abernathy, M.E., Dam, K.A., Esswein, S.R., Gristick, H.B., Malyutin, A.G., Sharaf, N.G., Huey-Tubman, K.E., Lee, Y.E., et al. (2020). Structural classification of neutralizing antibodies against the SARS-CoV-2 spike receptor-binding domain suggests vaccine and therapeutic strategies. bioRxiv : the preprint server for biology. Published online 2020/09/02 DOI:

10.1101/2020.08.30.273920.

Baum, A., Fulton, B.O., Wloga, E., Copin, R., Pascal, K.E., Russo, V., Giordano, S., Lanza, K., Negron, N., $\mathrm{Ni}, \mathrm{M}$., et al. (2020). Antibody cocktail to SARS-CoV-2 spike protein prevents rapid mutational escape seen with individual antibodies. Science. Published online 2020/06/17 DOI:

10.1126/science.abd0831.

Bestle, D., Heindl, M.R., Limburg, H., Van Lam van, T., Pilgram, O., Moulton, H., Stein, D.A., Hardes, K., Eickmann, M., Dolnik, O., et al. (2020). TMPRSS2 and furin are both essential for proteolytic activation of SARS-CoV-2 in human airway cells. Life science alliance. 3(9). Published online 2020/07/25 DOI: 10.26508/Isa.202000786. 
Bongiorno, E.K., Garcia, S.A., Sauma, S., and Hooper, D.C. (2017). Type 1 Immune Mechanisms Driven by the Response to Infection with Attenuated Rabies Virus Result in Changes in the Immune Bias of the Tumor Microenvironment and Necrosis of Mouse GL261 Brain Tumors. J Immunol. 198(11), 45134523. Published online 2017/05/04 DOI: 10.4049/jimmunol.1601444.

Brouwer, P.J.M., Caniels, T.G., van der Straten, K., Snitselaar, J.L., Aldon, Y., Bangaru, S., Torres, J.L., Okba, N.M.A., Claireaux, M., Kerster, G., et al. (2020). Potent neutralizing antibodies from COVID-19 patients define multiple targets of vulnerability. Science. Published online 2020/06/17 DOI: 10.1126/science.abc5902.

Buchholz, U.J., Bukreyev, A., Yang, L., Lamirande, E.W., Murphy, B.R., Subbarao, K., and Collins, P.L. (2004). Contributions of the structural proteins of severe acute respiratory syndrome coronavirus to protective immunity. Proc Natl Acad Sci U S A. 101(26), 9804-9809. Published online 2004/06/24 DOI: $10.1073 /$ pnas.0403492101.

Buchholz, U.J., Finke, S., and Conzelmann, K.K. (1999). Generation of bovine respiratory syncytial virus (BRSV) from cDNA: BRSV NS2 is not essential for virus replication in tissue culture, and the human RSV leader region acts as a functional BRSV genome promoter. J Virol. 73(1), 251-259.

Bukreyev, A., Lamirande, E.W., Buchholz, U.J., Vogel, L.N., Elkins, W.R., St Claire, M., Murphy, B.R., Subbarao, K., and Collins, P.L. (2004). Mucosal immunisation of African green monkeys (Cercopithecus aethiops) with an attenuated parainfluenza virus expressing the SARS coronavirus spike protein for the prevention of SARS. Lancet. 363(9427), 2122-2127. Published online 2004/06/29 DOI: 10.1016/s0140-6736(04)16501-x.

Cao, Y., Su, B., Guo, X., Sun, W., Deng, Y., Bao, L., Zhu, Q., Zhang, X., Zheng, Y., Geng, C., et al. (2020). Potent Neutralizing Antibodies against SARS-CoV-2 Identified by High-Throughput Single-Cell Sequencing of Convalescent Patients' B Cells. Cell. 182(1), 73-84.e16. Published online 2020/05/20 DOI: 10.1016/j.cell.2020.05.025.

Case, J.B., Rothlauf, P.W., Chen, R.E., Kafai, N.M., Fox, J.M., Smith, B.K., Shrihari, S., McCune, B.T., Harvey, I.B., Keeler, S.P., et al. (2020a). Replication-Competent Vesicular Stomatitis Virus Vaccine Vector Protects against SARS-CoV-2-Mediated Pathogenesis in Mice. Cell host \& microbe. Published online 2020/08/18 DOI: 10.1016/j.chom.2020.07.018.

Case, J.B., Rothlauf, P.W., Chen, R.E., Liu, Z., Zhao, H., Kim, A.S., Bloyet, L.M., Zeng, Q., Tahan, S., Droit, L., et al. (2020b). Neutralizing Antibody and Soluble ACE2 Inhibition of a ReplicationCompetent VSV-SARS-CoV-2 and a Clinical Isolate of SARS-CoV-2. Cell host \& microbe. Published online 2020/08/01 DOI: 10.1016/j.chom.2020.06.021.

Chi, X., Yan, R., Zhang, J., Zhang, G., Zhang, Y., Hao, M., Zhang, Z., Fan, P., Dong, Y., Yang, Y., et al. (2020). A neutralizing human antibody binds to the $\mathrm{N}$-terminal domain of the Spike protein of SARSCoV-2. Science. 369(6504), 650-655. Published online 2020/06/24 DOI: 10.1126/science.abc6952.

Cloutier, M., Nandi, M., Ihsan, A.U., Chamard, H.A., Ilangumaran, S., and Ramanathan, S. (2020). ADE and hyperinflammation in SARS-CoV2 infection- comparison with dengue hemorrhagic fever and feline infectious peritonitis. Cytokine. 136, 155256. DOI: https://doi.org/10.1016/j.cyto.2020.155256.

Conzelmann, K.K. (1998). Nonsegmented negative-strand RNA viruses: genetics and manipulation of viral genomes. Annu.Rev Genet. 32, 123-162.

Corbett, K.S., Edwards, D.K., Leist, S.R., Abiona, O.M., Boyoglu-Barnum, S., Gillespie, R.A., Himansu, S., Schäfer, A., Ziwawo, C.T., DiPiazza, A.T., et al. (2020). SARS-CoV-2 mRNA vaccine design enabled 
by prototype pathogen preparedness. Nature. Published online 2020/08/07 DOI: 10.1038/s41586020-2622-0.

Dai, L., Zheng, T., Xu, K., Han, Y., Xu, L., Huang, E., An, Y., Cheng, Y., Li, S., Liu, M., et al. (2020). A Universal Design of Betacoronavirus Vaccines against COVID-19, MERS, and SARS. Cell. 182(3), $722-$ 733.e711. DOI: 10.1016/j.cell.2020.06.035.

De Giovanni, M., Cutillo, V., Giladi, A., Sala, E., Maganuco, C.G., Medaglia, C., Di Lucia, P., Bono, E., Cristofani, C., Consolo, E., et al. (2020). Spatiotemporal regulation of type I interferon expression determines the antiviral polarization of CD4(+) T cells. Nat Immunol. 21(3), 321-330. Published online 2020/02/19 DOI: 10.1038/s41590-020-0596-6.

Dieterle, M.E., Haslwanter, D., Bortz, R.H., 3rd, Wirchnianski, A.S., Lasso, G., Vergnolle, O., Abbasi, S.A., Fels, J.M., Laudermilch, E., Florez, C., et al. (2020). A Replication-Competent Vesicular Stomatitis Virus for Studies of SARS-CoV-2 Spike-Mediated Cell Entry and Its Inhibition. Cell host \& microbe. Published online 2020/08/02 DOI: 10.1016/j.chom.2020.06.020.

Drosten, C., Günther, S., Preiser, W., van der Werf, S., Brodt, H.R., Becker, S., Rabenau, H., Panning, M., Kolesnikova, L., Fouchier, R.A., et al. (2003). Identification of a novel coronavirus in patients with severe acute respiratory syndrome. The New England journal of medicine. 348(20), 1967-1976. Published online 2003/04/12 DOI: 10.1056/NEJMoa030747.

Feng, L., Wang, Q., Shan, C., Yang, C., Feng, Y., Wu, J., Liu, X., Zhou, Y., Jiang, R., Hu, P., et al. (2020). An adenovirus-vectored COVID-19 vaccine confers protection from SARS-COV-2 challenge in rhesus macaques. Nature communications. 11(1), 4207. Published online 2020/08/23 DOI: 10.1038/s41467020-18077-5.

Finke, S., Mueller-Waldeck, R., and Conzelmann, K.K. (2003). Rabies virus matrix protein regulates the balance of virus transcription and replication. J Gen Virol. 84(Pt 6), 1613-1621.

Flanagan, E.B., Ball, L.A., and Wertz, G.W. (2000). Moving the glycoprotein gene of vesicular stomatitis virus to promoter-proximal positions accelerates and enhances the protective immune response. J Virol. 74(17), 7895-7902. Published online 2000/08/10 DOI: 10.1128/jvi.74.17.78957902.2000 .

Fukushi, S., Mizutani, T., Saijo, M., Kurane, I., Taguchi, F., Tashiro, M., and Morikawa, S. (2006). Evaluation of a novel vesicular stomatitis virus pseudotype-based assay for detection of neutralizing antibody responses to SARS-CoV. Journal of medical virology. 78(12), 1509-1512. Published online 2006/10/26 DOI: 10.1002/jmv.20732.

Gaudin, Y., Ruigrok, R.W., Tuffereau, C., Knossow, M., and Flamand, A. (1992). Rabies virus glycoprotein is a trimer. Virology. 187(2), 627-632. Published online 1992/04/01 DOI: 10.1016/00426822(92)90465-2.

Ge, P., Tsao, J., Schein, S., Green, T.J., Luo, M., and Zhou, Z.H. (2010). Cryo-EM model of the bulletshaped vesicular stomatitis virus. Science. 327(5966), 689-693.

Ghanem, A., and Conzelmann, K.K. (2016). G gene-deficient single-round rabies viruses for neuronal circuit analysis. Virus Res. 216, 41-54. Published online 2015/06/13 DOI:

10.1016/j.virusres.2015.05.023.

Ghanem, A., Kern, A., and Conzelmann, K.K. (2012). Significantly improved rescue of rabies virus from cDNA plasmids. Eur.J.Cell Biol. 91(1), 10-16. 
Hanika, A., Larisch, B., Steinmann, E., Schwegmann-Weßels, C., Herrler, G., and Zimmer, G. (2005). Use of influenza $C$ virus glycoprotein $\mathrm{HEF}$ for generation of vesicular stomatitis virus pseudotypes. $J$ Gen Virol. 86(Pt 5), 1455-1465. Published online 2005/04/16 DOI: 10.1099/vir.0.80788-0.

Hoepel, W., Chen, H.-J., Allahverdiyeva, S., Manz, X., Aman, J., Bonta, P., Brouwer, P., de Taeye, S., Caniels, T., van der Straten, K., et al. (2020). Anti-SARS-CoV-2 IgG from severely ill COVID-19 patients promotes macrophage hyper-inflammatory responses. bioRxiv : the preprint server for biology. 2020.2007.2013.190140. DOI: 10.1101/2020.07.13.190140.

Hoffmann, M., Kleine-Weber, H., and Pöhlmann, S. (2020a). A Multibasic Cleavage Site in the Spike Protein of SARS-CoV-2 Is Essential for Infection of Human Lung Cells. Molecular cell. 78(4), 779784.e775. Published online 2020/05/05 DOI: 10.1016/j.molcel.2020.04.022.

Hoffmann, M., Kleine-Weber, H., Schroeder, S., Kruger, N., Herrler, T., Erichsen, S., Schiergens, T.S., Herrler, G., Wu, N.H., Nitsche, A., et al. (2020b). SARS-CoV-2 Cell Entry Depends on ACE2 and TMPRSS2 and Is Blocked by a Clinically Proven Protease Inhibitor. Cell. Published online 2020/03/07 DOI: 10.1016/j.cell.2020.02.052.

Huo, J., Zhao, Y., Ren, J., Zhou, D., Duyvesteyn, H.M.E., Ginn, H.M., Carrique, L., Malinauskas, T., Ruza, R.R., Shah, P.N.M., et al. (2020). Neutralization of SARS-CoV-2 by Destruction of the Prefusion Spike. Cell host \& microbe. 28(3), 445-454.e446. DOI: https://doi.org/10.1016/i.chom.2020.06.010.

Jaimes, J.A., Millet, J.K., and Whittaker, G.R. (2020). Proteolytic Cleavage of the SARS-CoV-2 Spike Protein and the Role of the Novel S1/S2 Site. iScience. 23(6), 101212. Published online 2020/06/09 DOI: $10.1016 /$ j.isci.2020.101212.

Jeyanathan, M., Afkhami, S., Smaill, F., Miller, M.S., Lichty, B.D., and Xing, Z. (2020). Immunological considerations for COVID-19 vaccine strategies. Nat Rev Immunol. Published online 2020/09/06 DOI: 10.1038/s41577-020-00434-6.

Kapadia, S.U., Rose, J.K., Lamirande, E., Vogel, L., Subbarao, K., and Roberts, A. (2005). Long-term protection from SARS coronavirus infection conferred by a single immunization with an attenuated VSV-based vaccine. Virology. 340(2), 174-182. Published online 2005/07/27 DOI: 10.1016/j.virol.2005.06.016.

Kapadia, S.U., Simon, I.D., and Rose, J.K. (2008). SARS vaccine based on a replication-defective recombinant vesicular stomatitis virus is more potent than one based on a replication-competent vector. Virology. 376(1), 165-172. Published online 2008/04/09 DOI: 10.1016/j.virol.2008.03.002.

Kim, Y.I., Kim, S.G., Kim, S.M., Kim, E.H., Park, S.J., Yu, K.M., Chang, J.H., Kim, E.J., Lee, S., Casel, M.A.B., et al. (2020). Infection and Rapid Transmission of SARS-CoV-2 in Ferrets. Cell host \& microbe. Published online 2020/04/08 DOI: 10.1016/j.chom.2020.03.023.

Klingen, Y., Conzelmann, K.K., and Finke, S. (2008). Double-labeled rabies virus: live tracking of enveloped virus transport. J.Virol. 82(1), 237-245.

Kreer, C., Zehner, M., Weber, T., Ercanoglu, M.S., Gieselmann, L., Rohde, C., Halwe, S., Korenkov, M., Schommers, P., Vanshylla, K., et al. (2020). Longitudinal Isolation of Potent Near-Germline SARS-CoV2-Neutralizing Antibodies from COVID-19 Patients. Cell. Published online 2020/07/17 DOI: 10.1016/j.cell.2020.06.044.

Kremer, J.R., Mastronarde, D.N., and McIntosh, J.R. (1996). Computer Visualization of ThreeDimensional Image Data Using IMOD. Journal of structural biology. 116(1), 71-76. DOI:

https://doi.org/10.1006/jsbi.1996.0013. 
Ksiazek, T.G., Erdman, D., Goldsmith, C.S., Zaki, S.R., Peret, T., Emery, S., Tong, S.X., Urbani, C., Comer, J.A., Lim, W., et al. (2003). A novel coronavirus associated with severe acute respiratory syndrome. N. Engl. J. Med. 348(20), 1953-1966. DOI: 10.1056/NEJMoa030781.

Lan, J., Ge, J., Yu, J., Shan, S., Zhou, H., Fan, S., Zhang, Q., Shi, X., Wang, Q., Zhang, L., et al. (2020). Structure of the SARS-CoV-2 spike receptor-binding domain bound to the ACE2 receptor. Nature. 581(7807), 215-220. Published online 2020/04/01 DOI: 10.1038/s41586-020-2180-5.

Lawson, N.D., Stillman, E.A., Whitt, M.A., and Rose, J.K. (1995). Recombinant vesicular stomatitis viruses from DNA. Proc Natl Acad Sci U S A. 92(10), 4477-4481. Published online 1995/05/09.

Lee, W.S., Wheatley, A.K., Kent, S.J., and DeKosky, B.J. (2020). Antibody-dependent enhancement and SARS-CoV-2 vaccines and therapies. Nature microbiology. DOI: 10.1038/s41564-020-00789-5.

Lyles, D.S., McKenzie, M., and Parce, J.W. (1992). Subunit interactions of vesicular stomatitis virus envelope glycoprotein stabilized by binding to viral matrix protein. J Virol. 66(1), 349-358. Published online 1992/01/01 DOI: 10.1128/jvi.66.1.349-358.1992.

Mangeot, P.-E., Dollet, S., Girard, M., Ciancia, C., Joly, S., Peschanski, M., and Lotteau, V. (2011). Protein Transfer Into Human Cells by VSV-G-induced Nanovesicles. Molecular Therapy. 19(9), 16561666. DOI: https://doi.org/10.1038/mt.2011.138.

Matz, K.M., Marzi, A., and Feldmann, H. (2019). Ebola vaccine trials: progress in vaccine safety and immunogenicity. Expert review of vaccines. 18(12), 1229-1242. Published online 2019/11/30 DOI: 10.1080/14760584.2019.1698952.

Mebatsion, T., Finke, S., Weiland, F., and Conzelmann, K.K. (1997). A CXCR4/CD4 pseudotype rhabdovirus that selectively infects HIV-1 envelope protein-expressing cells. Cell. 90(5), 841-847.

Mebatsion, T., König, M., and Conzelmann, K.K. (1996). Budding of rabies virus particles in the absence of the spike glycoprotein. Cell. 84(6), 941-951.

Mebatsion, T., Weiland, F., and Conzelmann, K.K. (1999). Matrix protein of rabies virus is responsible for the assembly and budding of bullet-shaped particles and interacts with the transmembrane spike glycoprotein G. J Virol. 73(1), 242-250.

Melzer, M.K., Lopez-Martinez, A., and Altomonte, J. (2017). Oncolytic Vesicular Stomatitis Virus as a Viro-Immunotherapy: Defeating Cancer with a "Hammer" and "Anvil". Biomedicines. 5(1). Published online 2017/05/26 DOI: 10.3390/biomedicines5010008.

Mulligan, M.J., Lyke, K.E., Kitchin, N., Absalon, J., Gurtman, A., Lockhart, S., Neuzil, K., Raabe, V., Bailey, R., Swanson, K.A., et al. (2020). Phase $1 / 2$ study of COVID-19 RNA vaccine BNT162b1 in adults. Nature. DOI: 10.1038/s41586-020-2639-4.

Polack, F.P., Teng, M.N., Collins, P.L., Prince, G.A., Exner, M., Regele, H., Lirman, D.D., Rabold, R., Hoffman, S.J., Karp, C.L., et al. (2002). A role for immune complexes in enhanced respiratory syncytial virus disease. J Exp Med. 196(6), 859-865. Published online 2002/09/18 DOI: 10.1084/jem.20020781.

Premkumar, L., Segovia-Chumbez, B., Jadi, R., Martinez, D.R., Raut, R., Markmann, A., Cornaby, C., Bartelt, L., Weiss, S., Park, Y., et al. (2020). The receptor binding domain of the viral spike protein is an immunodominant and highly specific target of antibodies in SARS-CoV-2 patients. Science immunology. 5(48). Published online 2020/06/13 DOI: 10.1126/sciimmunol.abc8413. 
Puelles, V.G., Lutgehetmann, M., Lindenmeyer, M.T., Sperhake, J.P., Wong, M.N., Allweiss, L., Chilla, S., Heinemann, A., Wanner, N., Liu, S., et al. (2020). Multiorgan and Renal Tropism of SARS-CoV-2. The New England journal of medicine. Published online 2020/05/14 DOI: 10.1056/NEJMc2011400.

Riedel, C., Vasishtan, D., Prazak, V., Ghanem, A., Conzelmann, K.K., and Rumenapf, T. (2019). Cryo EM structure of the rabies virus ribonucleoprotein complex. Scientific reports. 9(1), 9639. Published online 2019/07/05 DOI: 10.1038/s41598-019-46126-7.

Roberts, A., Buonocore, L., Price, R., Forman, J., and Rose, J.K. (1999). Attenuated vesicular stomatitis viruses as vaccine vectors. J Virol. 73(5), 3723-3732. Published online 1999/04/10 DOI: 10.1128/jvi.73.5.3723-3732.1999.

Rockx, B., Kuiken, T., Herfst, S., Bestebroer, T., Lamers, M.M., Oude Munnink, B.B., de Meulder, D., van Amerongen, G., van den Brand, J., Okba, N.M.A., et al. (2020). Comparative pathogenesis of COVID-19, MERS, and SARS in a nonhuman primate model. Science. Published online 2020/04/19 DOI: $10.1126 /$ science.abb7314.

Rohaim, M.A., and Munir, M. (2020). A Scalable Topical Vectored Vaccine Candidate against SARSCoV-2. Vaccines. 8(3). Published online 2020/08/28 DOI: 10.3390/vaccines8030472.

Roldão, A., Mellado, M.C., Castilho, L.R., Carrondo, M.J., and Alves, P.M. (2010). Virus-like particles in vaccine development. Expert review of vaccines. 9(10), 1149-1176. Published online 2010/10/07 DOI: 10.1586/erv.10.115.

Rolls, M.M., Webster, P., Balba, N.H., and Rose, J.K. (1994). Novel infectious particles generated by expression of the vesicular stomatitis virus glycoprotein from a self-replicating RNA. Cell. 79(3), 497506. Published online 1994/11/04.

Roy, P., and Noad, R. (2009). Virus-like particles as a vaccine delivery system: myths and facts. Advances in experimental medicine and biology. 655, 145-158. Published online 2010/01/05 DOI: 10.1007/978-1-4419-1132-2_11.

Ruckwardt, T.J., Morabito, K.M., and Graham, B.S. (2019). Immunological Lessons from Respiratory Syncytial Virus Vaccine Development. Immunity. 51(3), 429-442. Published online 2019/09/19 DOI: 10.1016/j.immuni.2019.08.007.

Sahin, U., Muik, A., Derhovanessian, E., Vogler, I., Kranz, L.M., Vormehr, M., Baum, A., Pascal, K., Quandt, J., Maurus, D., et al. (2020). COVID-19 vaccine BNT162b1 elicits human antibody and TH1 Tcell responses. Nature. DOI: 10.1038/s41586-020-2814-7.

Schmidt, F., Weisblum, Y., Muecksch, F., Hoffmann, H.H., Michailidis, E., Lorenzi, J.C.C., Mendoza, P., Rutkowska, M., Bednarski, E., Gaebler, C., et al. (2020). Measuring SARS-CoV-2 neutralizing antibody activity using pseudotyped and chimeric viruses. J Exp Med. 217(11). Published online 2020/07/22 DOI: $10.1084 /$ jem.20201181.

Schnell, M.J., Buonocore, L., Boritz, E., Ghosh, H.P., Chernish, R., and Rose, J.K. (1998). Requirement for a non-specific glycoprotein cytoplasmic domain sequence to drive efficient budding of vesicular stomatitis virus. Embo j. 17(5), 1289-1296. Published online 1998/04/18 DOI:

10.1093/emboj/17.5.1289.

Schnell, M.J., Mebatsion, T., and Conzelmann, K.K. (1994). Infectious rabies viruses from cloned cDNA. EMBO J. 13(18), 4195-4203. 
Schuhmann, K.M., Pfaller, C.K., and Conzelmann, K.K. (2011). The measles virus V protein binds to p65 (RelA) to suppress NF-kappaB activity. J.Virol. 85(7), 3162-3171.

Shang, J., Ye, G., Shi, K., Wan, Y., Luo, C., Aihara, H., Geng, Q., Auerbach, A., and Li, F. (2020). Structural basis of receptor recognition by SARS-CoV-2. Nature. Published online 2020/04/01 DOI: 10.1038/s41586-020-2179-y.

Shi, J., Wen, Z., Zhong, G., Yang, H., Wang, C., Huang, B., Liu, R., He, X., Shuai, L., Sun, Z., et al. (2020). Susceptibility of ferrets, cats, dogs, and other domesticated animals to SARS-coronavirus 2. Science. Published online 2020/04/10 DOI: 10.1126/science.abb7015.

Sissoeff, L., Mousli, M., England, P., and Tuffereau, C. (2005). Stable trimerization of recombinant rabies virus glycoprotein ectodomain is required for interaction with the p75NTR receptor. J Gen Virol. 86(Pt 9), 2543-2552. Published online 2005/08/16 DOI: 10.1099/vir.0.81063-0.

Sun, W., Leist, S.R., McCroskery, S., Liu, Y., Slamanig, S., Oliva, J., Amanat, F., Schaefer, A., Dinnon, K., Garcia-Sastre, A., et al. (2020a). Newcastle disease virus (NDV) expressing the spike protein of SARSCoV-2 as vaccine candidate. bioRxiv : the preprint server for biology. Published online 2020/08/04 DOI: 10.1101/2020.07.26.221861.

Sun, W., McCroskery, S., Liu, W.C., Leist, S.R., Liu, Y., Albrecht, R.A., Slamanig, S., Oliva, J., Amanat, F., Schaefer, A., et al. (2020b). A Newcastle disease virus (NDV) expressing membrane-anchored spike as a cost-effective inactivated SARS-CoV-2 vaccine. bioRxiv : the preprint server for biology. Published online 2020/08/09 DOI: 10.1101/2020.07.30.229120.

Suthar, M.S., Zimmerman, M.G., Kauffman, R.C., Mantus, G., Linderman, S.L., Hudson, W.H., Vanderheiden, A., Nyhoff, L., Davis, C.W., Adekunle, O., et al. (2020). Rapid Generation of Neutralizing Antibody Responses in COVID-19 Patients. Cell reports. Medicine. 1(3), 100040. Published online 2020/08/25 DOI: 10.1016/j.xcrm.2020.100040.

Szomolanyi-Tsuda, E., and Welsh, R.M. (1998). T-cell-independent antiviral antibody responses. Current opinion in immunology. 10(4), 431-435. Published online 1998/09/02 DOI: 10.1016/s09527915(98)80117-9.

Tai, W., He, L., Zhang, X., Pu, J., Voronin, D., Jiang, S., Zhou, Y., and Du, L. (2020). Characterization of the receptor-binding domain (RBD) of 2019 novel coronavirus: implication for development of RBD protein as a viral attachment inhibitor and vaccine. Cellular \& molecular immunology. Published online 2020/03/24 DOI: 10.1038/s41423-020-0400-4.

Thorp, H.H. (2020). A dangerous rush for vaccines. Science. 369(6506), 885. Published online 2020/08/15 DOI: 10.1126/science.abe3147.

Tian, X., Li, C., Huang, A., Xia, S., Lu, S., Shi, Z., Lu, L., Jiang, S., Yang, Z., Wu, Y., et al. (2020). Potent binding of 2019 novel coronavirus spike protein by a SARS coronavirus-specific human monoclonal antibody. Emerging microbes \& infections. 9(1), 382-385. Published online 2020/02/18 DOI: 10.1080/22221751.2020.1729069.

van den Pol, A.N., Mao, G., Chattopadhyay, A., Rose, J.K., and Davis, J.N. (2017). Chikungunya, Influenza, Nipah, and Semliki Forest Chimeric Viruses with Vesicular Stomatitis Virus: Actions in the Brain. J Virol. 91(6). Published online 2017/01/13 DOI: 10.1128/jvi.02154-16.

Walls, A.C., Park, Y.J., Tortorici, M.A., Wall, A., McGuire, A.T., and Veesler, D. (2020). Structure, Function, and Antigenicity of the SARS-CoV-2 Spike Glycoprotein. Cell. 181(2), 281-292.e286. Published online 2020/03/11 DOI: 10.1016/j.cell.2020.02.058. 
Walsh, E.E., Frenck, R., Falsey, A.R., Kitchin, N., Absalon, J., Gurtman, A., Lockhart, S., Neuzil, K., Mulligan, M.J., Bailey, R., et al. (2020). RNA-Based COVID-19 Vaccine BNT162b2 Selected for a Pivotal Efficacy Study. medRxiv : the preprint server for health sciences. Published online 2020/08/26 DOI: 10.1101/2020.08.17.20176651.

Wang, C., Li, W., Drabek, D., Okba, N.M.A., van Haperen, R., Osterhaus, A., van Kuppeveld, F.J.M., Haagmans, B.L., Grosveld, F., and Bosch, B.J. (2020). A human monoclonal antibody blocking SARSCoV-2 infection. Nature communications. 11(1), 2251. Published online 2020/05/06 DOI: 10.1038/s41467-020-16256-y.

Wang, Q., Zhang, L., Kuwahara, K., Li, L., Liu, Z., Li, T., Zhu, H., Liu, J., Xu, Y., Xie, J., et al. (2016). Immunodominant SARS Coronavirus Epitopes in Humans Elicited both Enhancing and Neutralizing Effects on Infection in Non-human Primates. ACS infectious diseases. 2(5), 361-376. Published online 2016/09/15 DOI: 10.1021/acsinfecdis.6b00006.

Weisblum, Y., Schmidt, F., Zhang, F., DaSilva, J., Poston, D., Lorenzi, J.C.C., Muecksch, F., Rutkowska, M., Hoffmann, H.H., Michailidis, E., et al. (2020). Escape from neutralizing antibodies by SARS-CoV-2 spike protein variants. bioRxiv : the preprint server for biology. Published online 2020/08/04 DOI: 10.1101/2020.07.21.214759.

WHO, 2020. Draft landscape of COVID-19 candidate vaccines 30 September 2020, WHO publications, 2020 ed.

Wrapp, D., De Vlieger, D., Corbett, K.S., Torres, G.M., Wang, N., Van Breedam, W., Roose, K., van Schie, L., Hoffmann, M., Pohlmann, S., et al. (2020a). Structural Basis for Potent Neutralization of Betacoronaviruses by Single-Domain Camelid Antibodies. Cell. Published online 2020/05/07 DOI: 10.1016/j.cell.2020.04.031.

Wrapp, D., Wang, N., Corbett, K.S., Goldsmith, J.A., Hsieh, C.L., Abiona, O., Graham, B.S., and McLellan, J.S. (2020b). Cryo-EM structure of the 2019-nCoV spike in the prefusion conformation. Science. 367(6483), 1260-1263. Published online 2020/02/23 DOI: 10.1126/science.abb2507.

Wu, F., Zhao, S., Yu, B., Chen, Y.M., Wang, W., Song, Z.G., Hu, Y., Tao, Z.W., Tian, J.H., Pei, Y.Y., et al. (2020). A new coronavirus associated with human respiratory disease in China. Nature. 579(7798), 265-269. Published online 2020/02/06 DOI: 10.1038/s41586-020-2008-3.

Wu, S., Zhong, G., Zhang, J., Shuai, L., Zhang, Z., Wen, Z., Wang, B., Zhao, Z., Song, X., Chen, Y., et al. (2020). A single dose of an adenovirus-vectored vaccine provides protection against SARS-CoV-2 challenge. Nature communications. 11(1), 4081. Published online 2020/08/17 DOI: 10.1038/s41467020-17972-1.

Yahalom-Ronen, Y., Tamir, H., Melamed, S., Politi, B., Shifman, O., Achdout, H., Vitner, E.B., Israeli, O., Milrot, E., Stein, D., et al. (2020). A single dose of recombinant VSV- $\Delta G$-spike vaccine provides protection against SARS-CoV-2 challenge. bioRxiv : the preprint server for biology. 2020.2006.2018.160655. DOI: 10.1101/2020.06.18.160655.

Yan, R., Zhang, Y., Li, Y., Xia, L., Guo, Y., and Zhou, Q. (2020). Structural basis for the recognition of SARS-CoV-2 by full-length human ACE2. Science. 367(6485), 1444-1448. Published online 2020/03/07 DOI: $10.1126 /$ science.abb2762.

Yuan, M., Wu, N.C., Zhu, X., Lee, C.D., So, R.T.Y., Lv, H., Mok, C.K.P., and Wilson, I.A. (2020). A highly conserved cryptic epitope in the receptor-binding domains of SARS-CoV-2 and SARS-CoV. Science. Published online 2020/04/05 DOI: 10.1126/science.abb7269. 
Zagouras, P., and Rose, J.K. (1993). Dynamic equilibrium between vesicular stomatitis virus glycoprotein monomers and trimers in the Golgi and at the cell surface. J Virol. 67(12), 7533-7538. Published online 1993/12/01 DOI: 10.1128/jvi.67.12.7533-7538.1993.

Zang, R., Gomez Castro, M.F., McCune, B.T., Zeng, Q., Rothlauf, P.W., Sonnek, N.M., Liu, Z., Brulois, K.F., Wang, X., Greenberg, H.B., et al. (2020). TMPRSS2 and TMPRSS4 promote SARS-CoV-2 infection of human small intestinal enterocytes. Science immunology. 5(47). Published online 2020/05/15 DOI: 10.1126/sciimmunol.abc3582.

Zemp, F., Rajwani, J., and Mahoney, D.J. (2018). Rhabdoviruses as vaccine platforms for infectious disease and cancer. Biotechnology \& genetic engineering reviews. 34(1), 122-138. Published online 2018/05/22 DOI: 10.1080/02648725.2018.1474320.

Zhou, P., Yang, X.L., Wang, X.G., Hu, B., Zhang, L., Zhang, W., Si, H.R., Zhu, Y., Li, B., Huang, C.L., et al. (2020). A pneumonia outbreak associated with a new coronavirus of probable bat origin. Nature. 579(7798), 270-273. Published online 2020/02/06 DOI: 10.1038/s41586-020-2012-7.

Zhu, N., Zhang, D., Wang, W., Li, X., Yang, B., Song, J., Zhao, X., Huang, B., Shi, W., Lu, R., et al. (2020). A Novel Coronavirus from Patients with Pneumonia in China, 2019. The New England journal of medicine. 382(8), 727-733. Published online 2020/01/25 DOI: 10.1056/NEJMoa2001017.

Zost, S.J., Gilchuk, P., Case, J.B., Binshtein, E., Chen, R.E., Nkolola, J.P., Schäfer, A., Reidy, J.X., Trivette, A., Nargi, R.S., et al. (2020). Potently neutralizing and protective human antibodies against SARS-CoV2. Nature. Published online 2020/07/16 DOI: 10.1038/s41586-020-2548-6. 


\section{Figure Legends}

Fig. 1. Design and expression of minispike.

(A) Schematic representation of the SARS-CoV-2 spike protein (adapted from Wrapp et al., 2020), and the chimeric rhabdovirus minispike containing a hlgG signal sequence (SS) the SARS-CoV-2 RBD (green), and the RABV G stem/anchor sequence (red). Two consensus Ngylcosylation sites are indicated. S2', S2' protease cleavage sites, TM transmembrane domain, NTD N-terminal domain, CT cytoplasmic tail.

(B) Complex $\mathrm{N}$ glycosylation of minispike protein. Extracts from HEK293T cells transfected with pCR3-minispike or pCAGGs-RABV-G were treated with PNGase $F(+F)$, which cleaves off all $\mathrm{N}$-linked oligosaccharides, left untreated (-) or treated with Endoglycosidase $\mathrm{H}(+\mathrm{H})$, unable to cleave complex sugars. Both minispike and RABV $G$ acquire complex sugars, indicating transport through the Golgi apparatus. Minispike and $\mathrm{G}$ proteins were visualized by incubation with HCA-5 serum, recognizing the common C-tail.

(C) Surface expression of minispike as revealed by staining of live HEK293T cells transfected with pCR3-minispike or pCG S $\triangle C 19$, a C-terminally truncated SARS-CoV-2 S protein, with a representative patient serum 1:400 (green). Acetone-fixed and permeabilized cells expressing minispike were in addition stained with HCA-5 recognizing the RABV-derived stem-anchor (red).

\section{Fig. 2. Characterization of minispike rhabdoviruses.}

(A) Schematic of VSV $\Delta G$ and RABV $\Delta G$ constructs used here.

(B) Incorporation of minispike in VSV envelopes. Cell-free minispike-encoding VSV $\Delta G$ viruses were generated in HEK293T cells expressing VSV G from transfected pCAGGS-VSV G for 6 or $24 \mathrm{hrs}$ prior to infection, or in stable BHK-G43 cells (VSVAG-trimini-eGFP) induced at the time of infection were purified by ultracentrifugation. Lanes were loaded with 1 million infectious units of G-containing infectious viruses, and the same volume of non-infectious viruses (no G). Blots were incubated with serum HCA-5 recognizing the RABV G-derived C-tail of the minispike (upper panel) or with anti-VSV serum recognizing viral $N, M$, and $G$ proteins (lower panel). Note that $\mathrm{G} 24 \mathrm{~h}$ preparation contains $\mathrm{G}$ vesicles (see Fig. 3).

(C) Incorporation of minispike in RABV SAD envelopes. Cell-free SAD $\triangle G$-virus particles as indicated were generated in HEK293T cells in the absence or presence of RABV SAD G. Lanes were loaded with 1 million infectious units each, blots were incubated with HCA-5 recognizing the cytoplasmic tails of minispike and SAD $G$ (upper panel) and anti-RABV $P$ serum to determine virus load (lower panel). Quantification of band intensities indicates competition of minispike and SAD G for incorporation into virions.

\section{Fig. 3. Characterization of minispike VLPs and mosaic viruses by cryo-EM.}

Slices through cryo electron tomograms of minispike-encoding VSV (A) and RABV (B) replicons generated in the presence of the autologous $G$ proteins (left panel) or in the absence (right panel) indicated. Rhabdovirus particles are covered by a dense array of surface protrusions, which appears more heterogenous in the presence of $G$ proteins. (C) VSV $\Delta G$ virions produced in the presence of VSV G contain virions with mosaic envelope and 
G-coated non-viral vesicles (Gesicles). (D) Length distribution of surface proteins in mosaic RABV viruses ( $\mathrm{G}+$ minispike) and particles presenting individual proteins.

\section{Fig. 4. Virus minispike presents conformational RBD epitopes.}

(A) Cells infected with VSVDG-minispike-eGFP (green) are recognized by IgG of S ELISApositive patients (red), in contrast to a control virus expressing blue fluorescent protein (VSVDG-BFP). Live unpermeabilized BHK-21 cells infected at low $\mathrm{MOI}$ and cultured over night at $32^{\circ} \mathrm{C}$ were incubated with patient serum (pat. ID 84; for other sera see Fig. S1) and stained with anti-human IgG Alexa 555, to reveal cell surface expression of minispike. 200x magnification.

(B) Cells infected with a RABV replicon expressing minispike (green) are recognized by IgG of S ELISA-positive patients (red). Live unpermeabilized VeroE6 cells were infected with SAD $\Delta G$ minispike-mNeongreen, incubated over night at $37^{\circ} \mathrm{C}$ and stained as described for (A). 1000 $x$ magnification.

(C) Poor recognition of denatured minispike protein by patient immune sera. VSV $\Delta$ G-eGFP virions pseudotyped with full length wt $\mathrm{S}$, a C-terminally truncated $\mathrm{S}(\mathrm{S} \Delta \mathrm{C}$ ) or a V5-tagged $\mathrm{S}$ protein (S-V5) were processed for denaturing SDS Western blot and probed with a representative patient serum (Pat. \#84). In contrast to the full length S proteins, denatured minispike was not readily recognized by human serum IgG. In the lower panel minispike expression was controlled by additional incubation of the same blot with HCA-5 peptide serum recognizing the $C$-tail present in SAD G and minispike.

Fig. 5. Vaccination with VSV $\Delta$ G-minispike-eGFP elicits potent SARS-CoV-2 neutralizing antibodies.

(A) Immunization Scheme. BALB/c mice were immunized i.m. with $1 \times 10^{6}$ infectious units of VSV G-complemented VSVDG-minispike-eGFP and controls including VSV G-complemented VSV $\triangle$ G-eGFP, or PBS. Twenty-eight days after immunization serum was collected from 4 vaccinated mice, while 8 mice received an i.m. boost immunization with the same dose of virus.

(B) Serum neutralization tests performed with a clinical isolate of SARS-CoV-2. The neutralizing titer of sera from vaccinated and control mice as indicated is expressed as the reciprocal of the highest dilution at which no cytopathic effect was observed. Each point represents data from one animal at the indicated time points. The bars show the mean from each group and the error bars represent standard deviations. Significant neutralizing activity was observed in mice receiving only a prime vaccination (day 28 , light blue). A boost immunization further significantly enhanced neutralizing titers (days 35 and 56).

(C) Neutralization of $\operatorname{VSV} \Delta \mathrm{G}(\mathrm{S})$ pseudotype viruses by individual mouse sera. Mouse sera collected on day 28 (receiving prime immunization only) or at 35 and 56 days (receiving prime and boost immunization) were serially diluted as indicated and analyzed for neutralization VSV(S) pseudotype particles. GFP-encoding pseudotype virions were incubated with increasing dilutions of mouse sera or medium control before infection of VeroE6 cells. The graph shows percentage of GFP-positive cells in relation to medium controls (100\%) and in dependence of dilution. Data points represent the average of three 
technical replicates, bars indicate standard deviation, and statistical significance was determined by one-way ANOVA.

Fig. 6. Similar virus-neutralizing titers in vaccinated mice and COVID-19 patients. VSV $\Delta G(S)$ neutralization activity of sera from vaccinated mice and human immune sera tested positive for $S$ antibodies by ELISA were compared. The graph shows percentage of GFP-positive cells in relation to medium controls and in dependence of dilution. All ELISA-positive human sera revealed VSV(S)-neutralizing activity (see Fig. S2) and are included in the grey boxes showing activity at the indicated dilutions. Primed mice (d28) exhibited neutralizing activity comparable to those of human patients, while boosted mice (d35 and d56) exhibited superior activity. Bottom and top of each box represent the first and third quartiles respectively. Whiskers represent the lowest and highest data points of the lower and upper quartile respectively. Student's t-test and One-way ANOVA were performed to determine statistical significance.

\section{Supplementary Figures}

Fig. S1 (related to Fig. 4)

Recognition of VSV-expressed minispike by patient sera. Vero E6 cells were infected with VSV- $\triangle$ G-bimini overnight at $32^{\circ} \mathrm{C}$, fixed in $4 \%$ PFA and permeabilized with $0.05 \%$ Saponine followed by incubation with different S ELISA-positive sera of COVID-19 patients, and HCA- 5 as a control for minispike expression. In contrast to a human negative control serum, all patient sera stained cells expressing minispike with anti-human IgG $(\mathrm{H}+\mathrm{L})$ Alexa 488 (green). ToPro3 (magenta) was used to counterstain nuclei.

Fig. S2. (related to Fig. 6)

Characterization of COVID-19 patient sera. (A) ELISA IgG ratio of sera (B) VSV(S) neutralizing activity of human sera. Graph shows reduction of ffu of VSVeGFP- $\Delta$ G-GLuc $S$ pseudotype viruses after incubation with sera at the indicated dilutions. (C) Comparison of ELISA titers and neutralizing activity at 1:200 dilution. 
Fig. 1

\section{A}

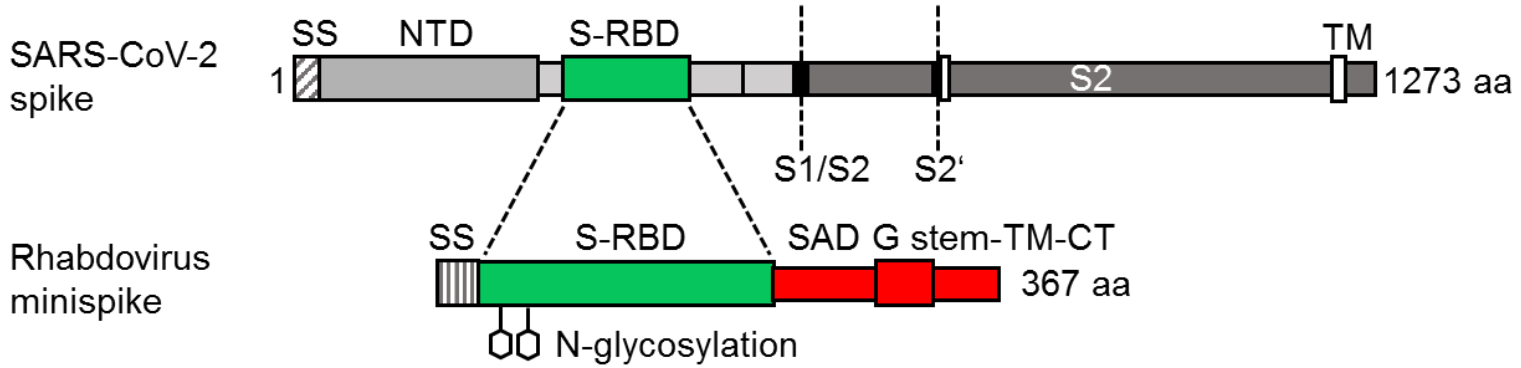

B

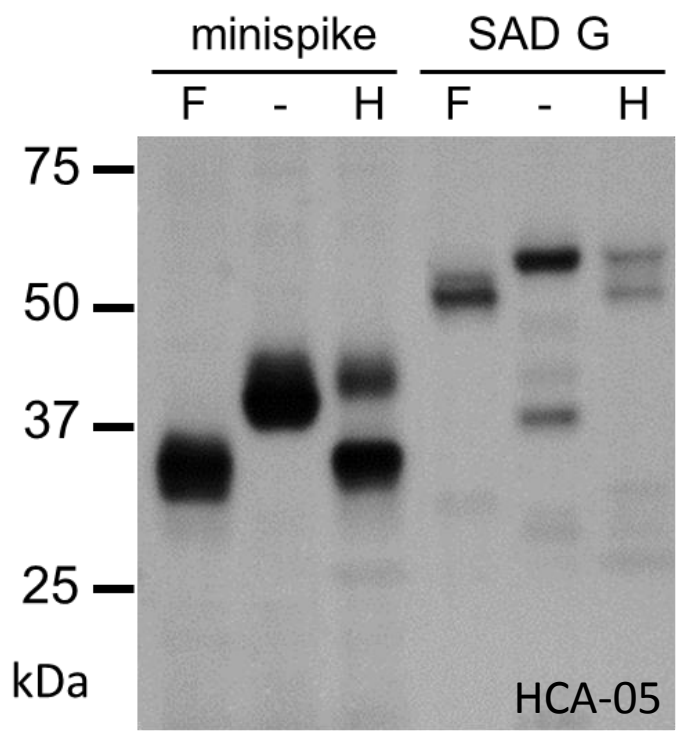

C

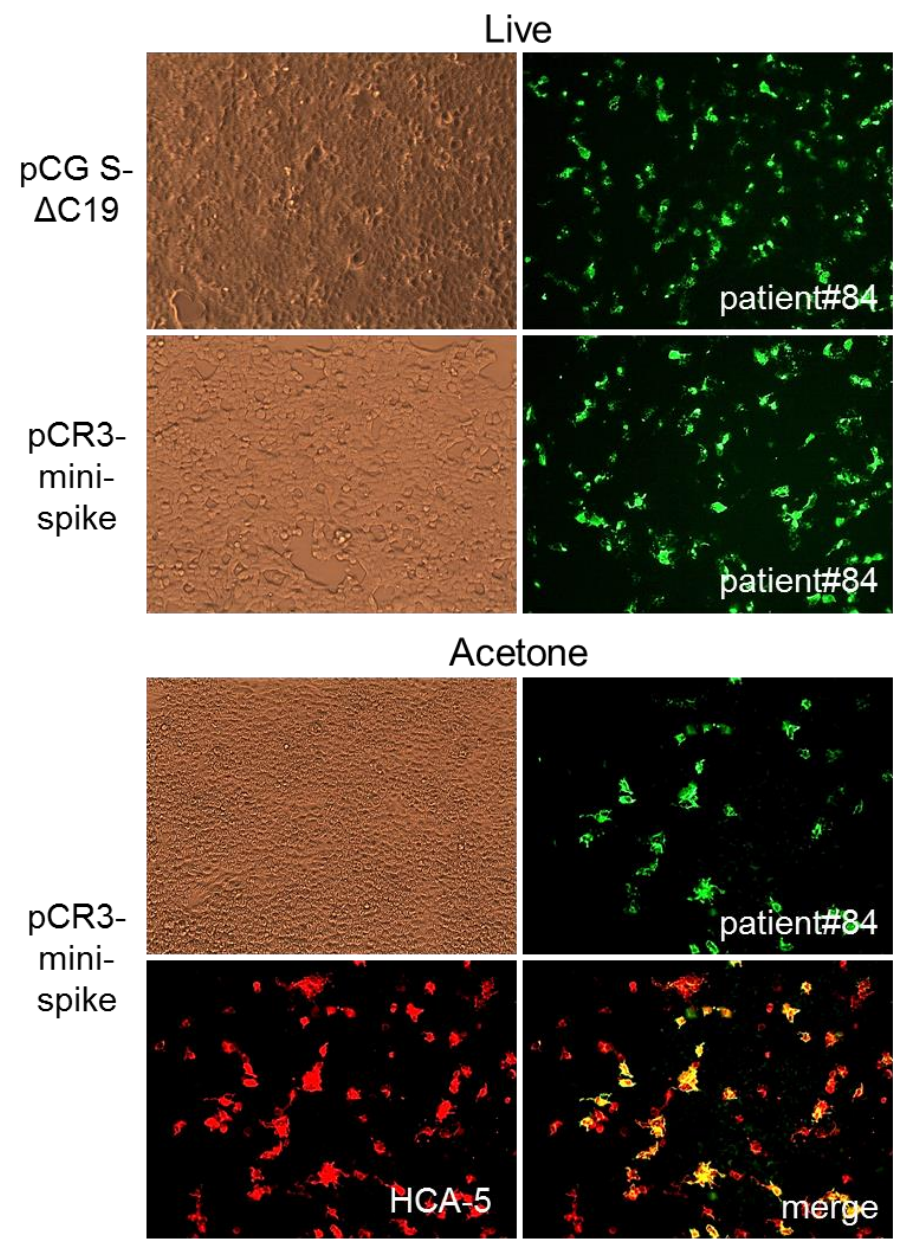


Fig. 2

A

$\underline{\text { VSV } \triangle G}$

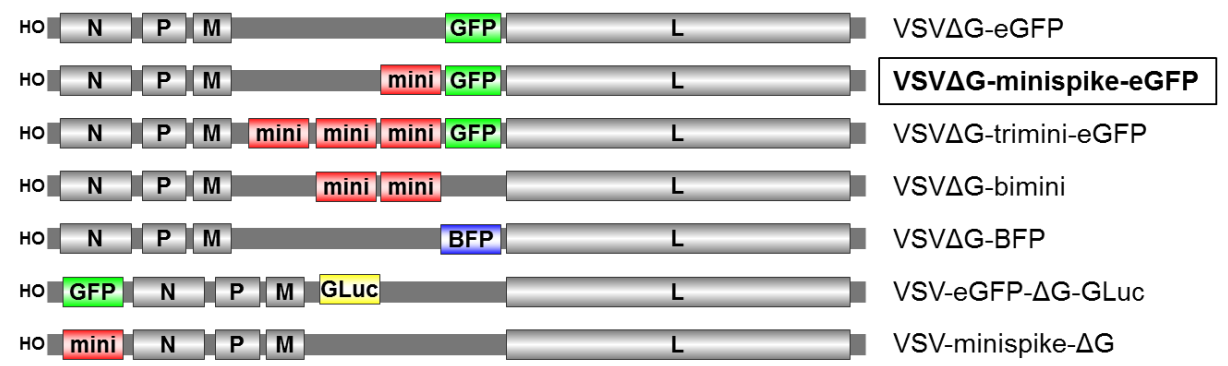

\section{RABV $\triangle \mathrm{G}$}

HO $\mathrm{N} P \mathrm{M}$

neon

SAD $\Delta$ G-mNeonGreen

HO $\quad \mathrm{N} \quad \mathrm{P}, \mathrm{M}$

mini neon

SAD $\Delta$ G-minispike-mNeonGreen

HO $\quad$ N $\quad P \quad M$

B
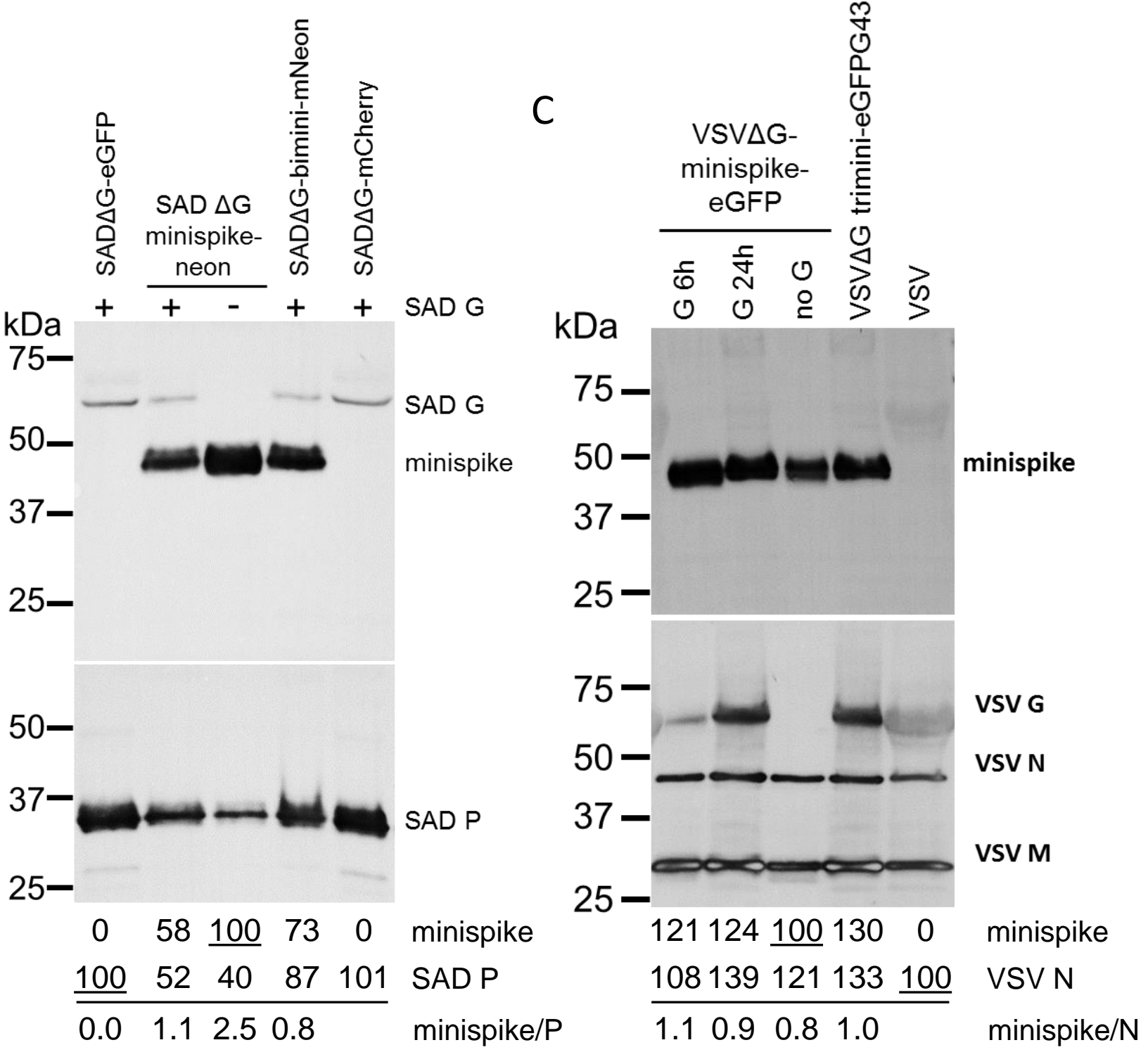
Fig. 3

\section{G + minispike}

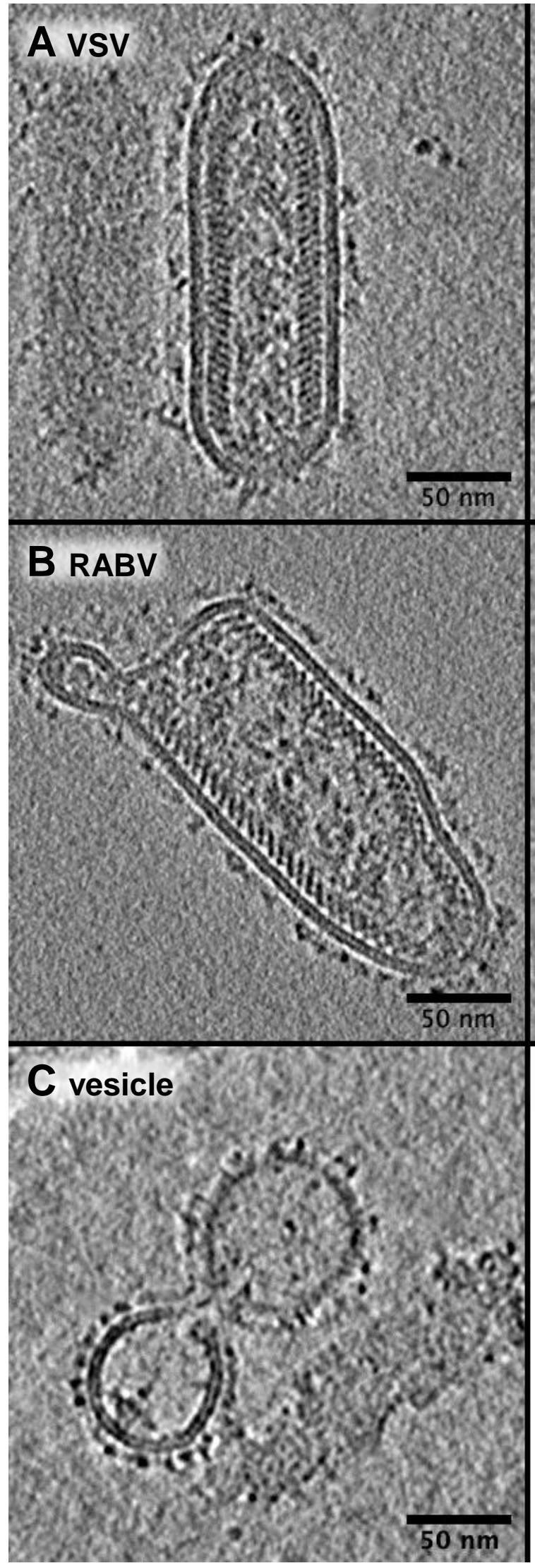

minispike
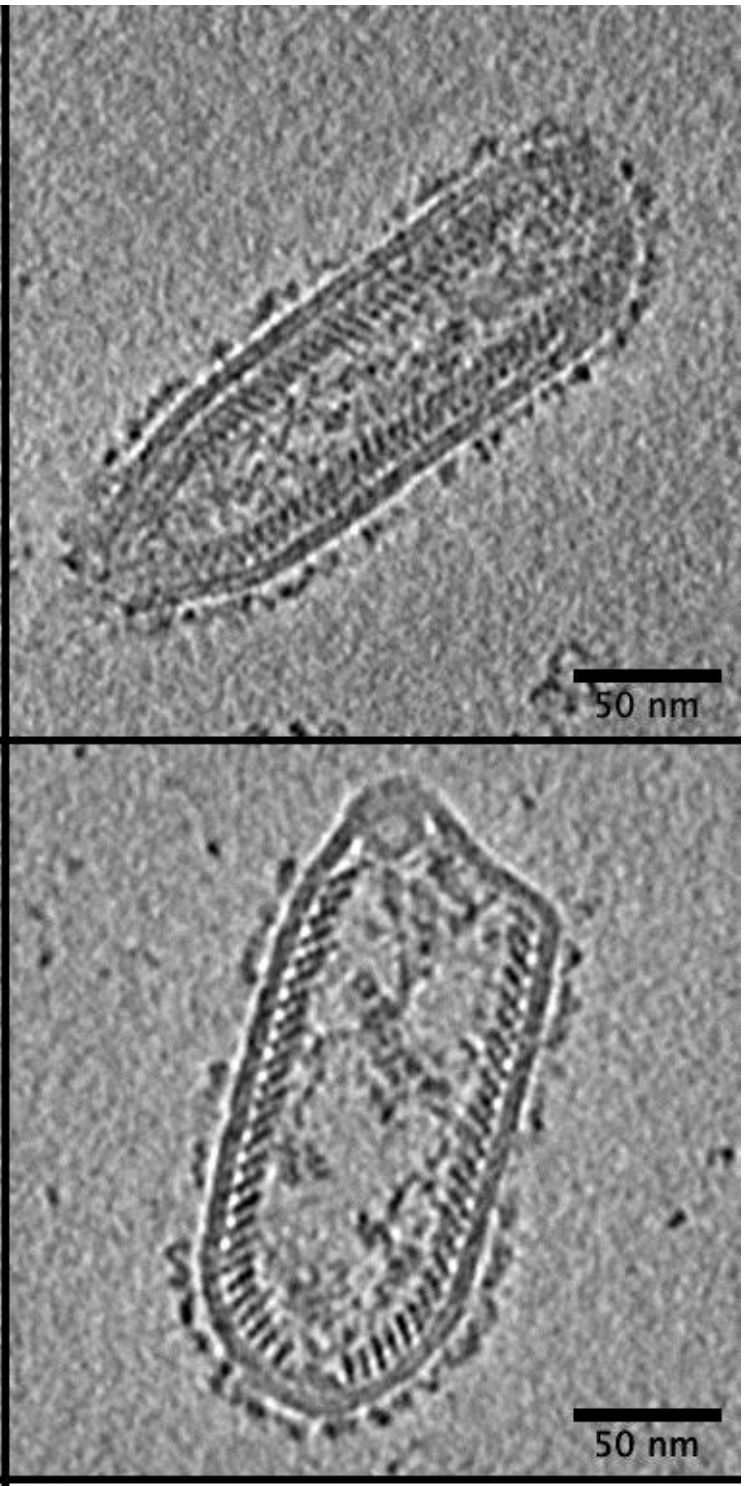

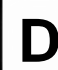

12

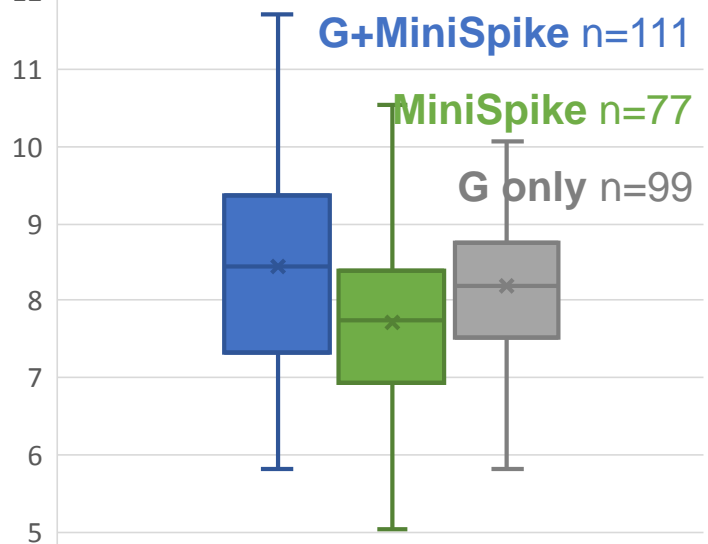


Fig. 4

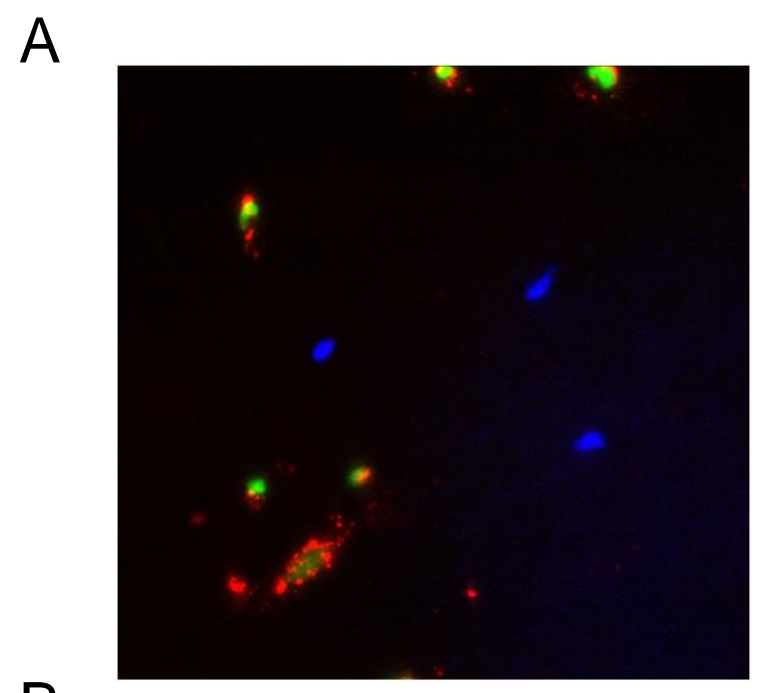

C
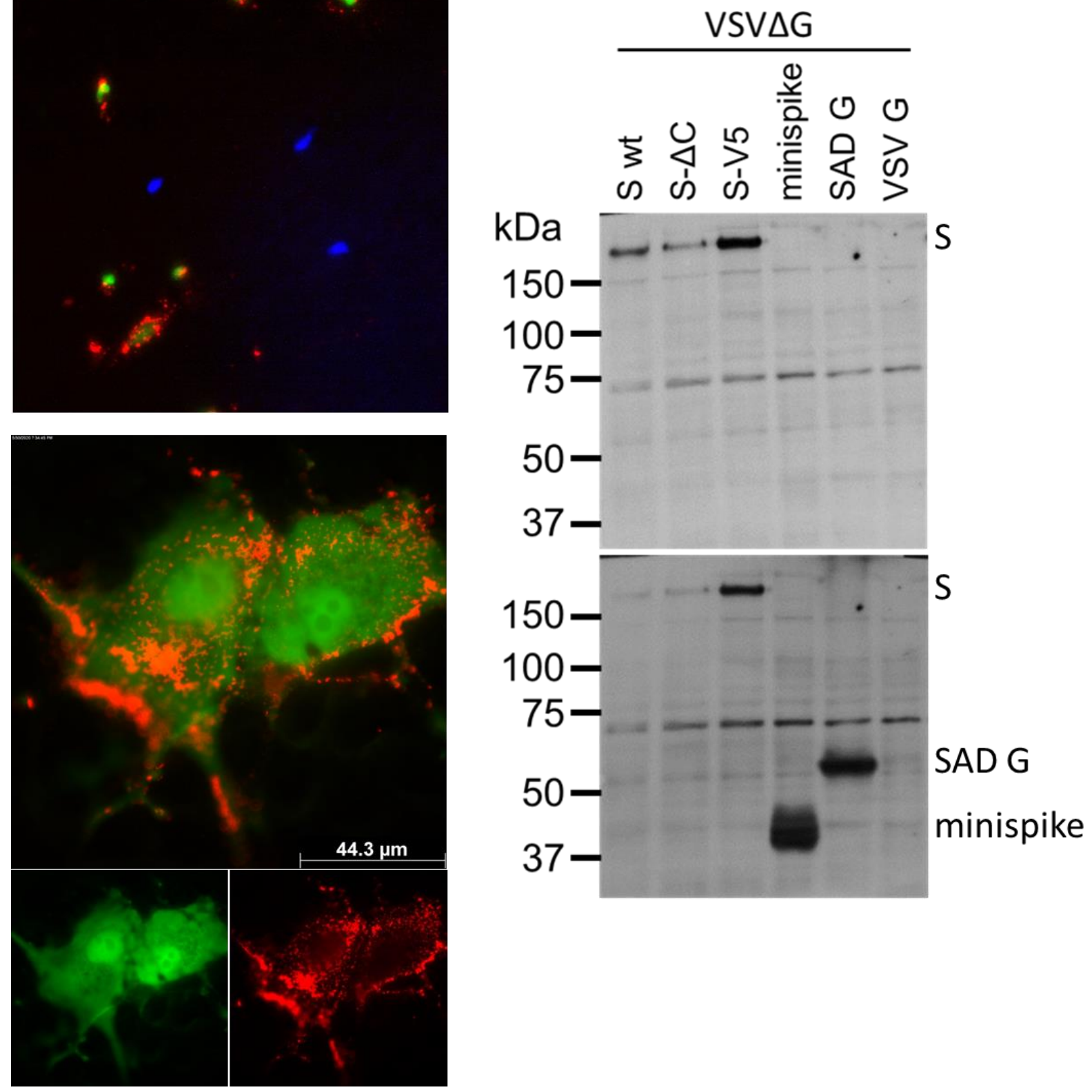
Fig. 5

A

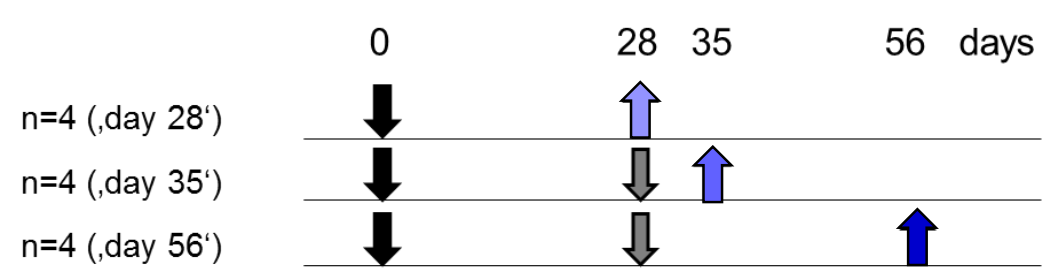

$\downarrow$ prime $\preceq$ boost $\}$ serum

B
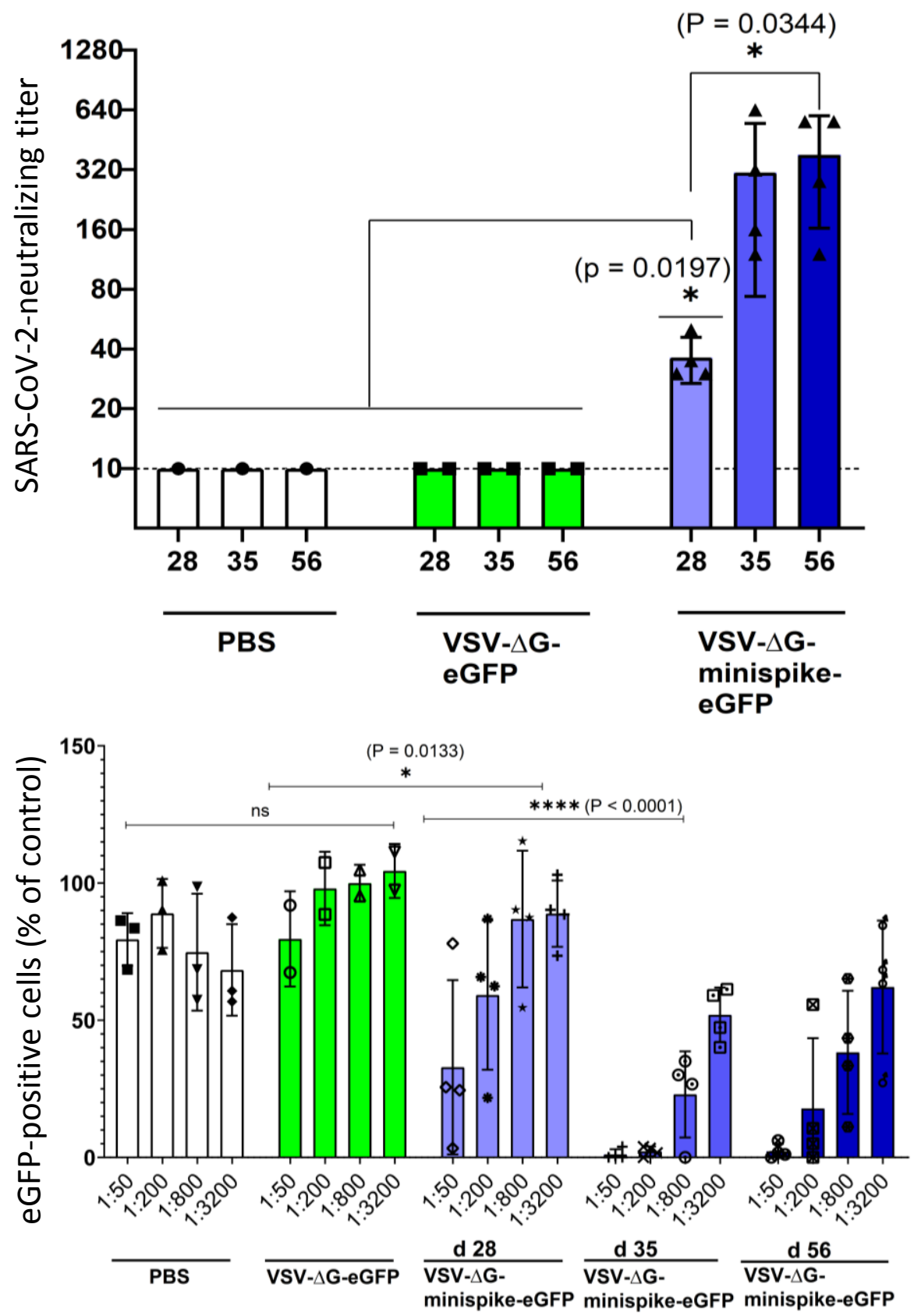
Fig. 6

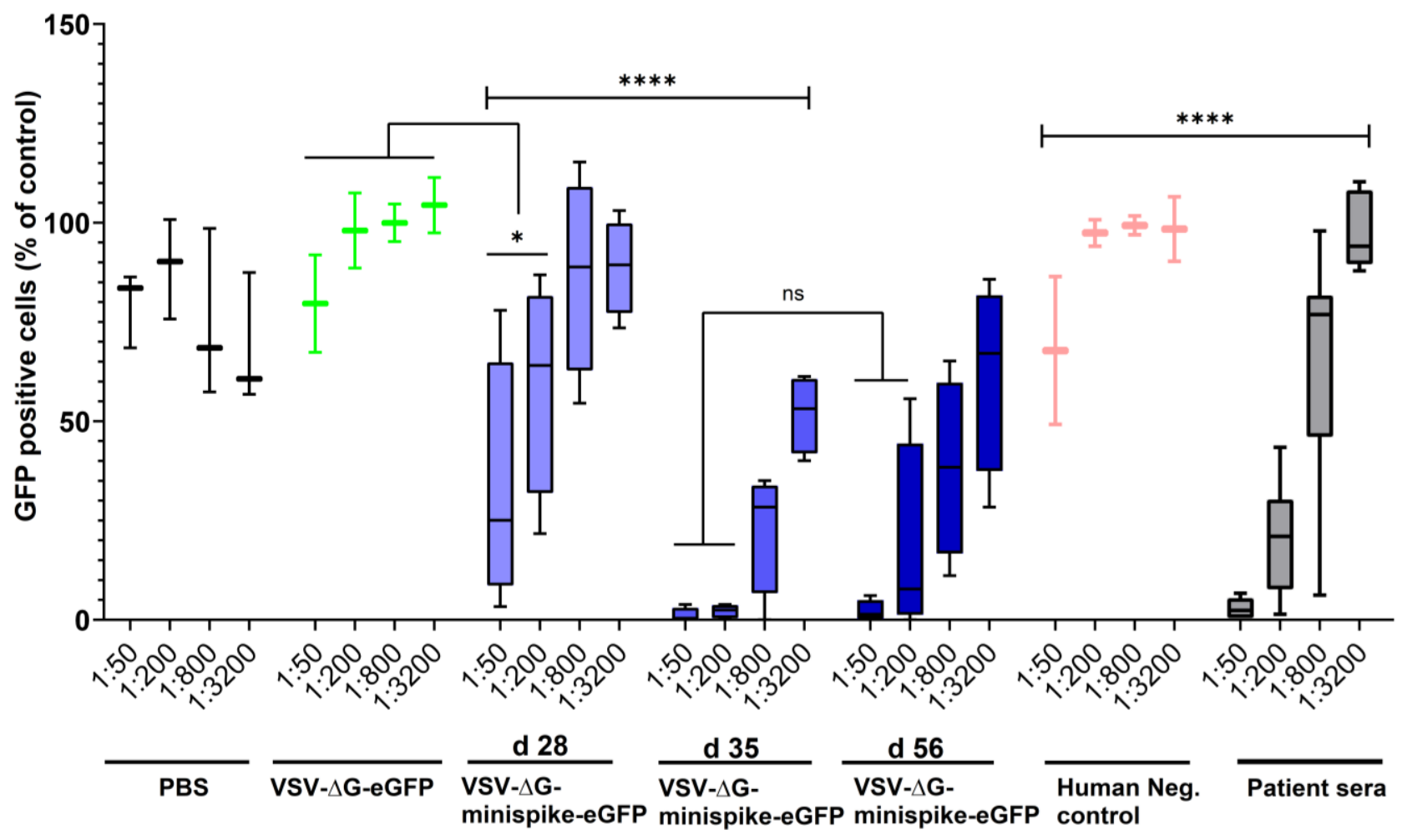


Fig. S1

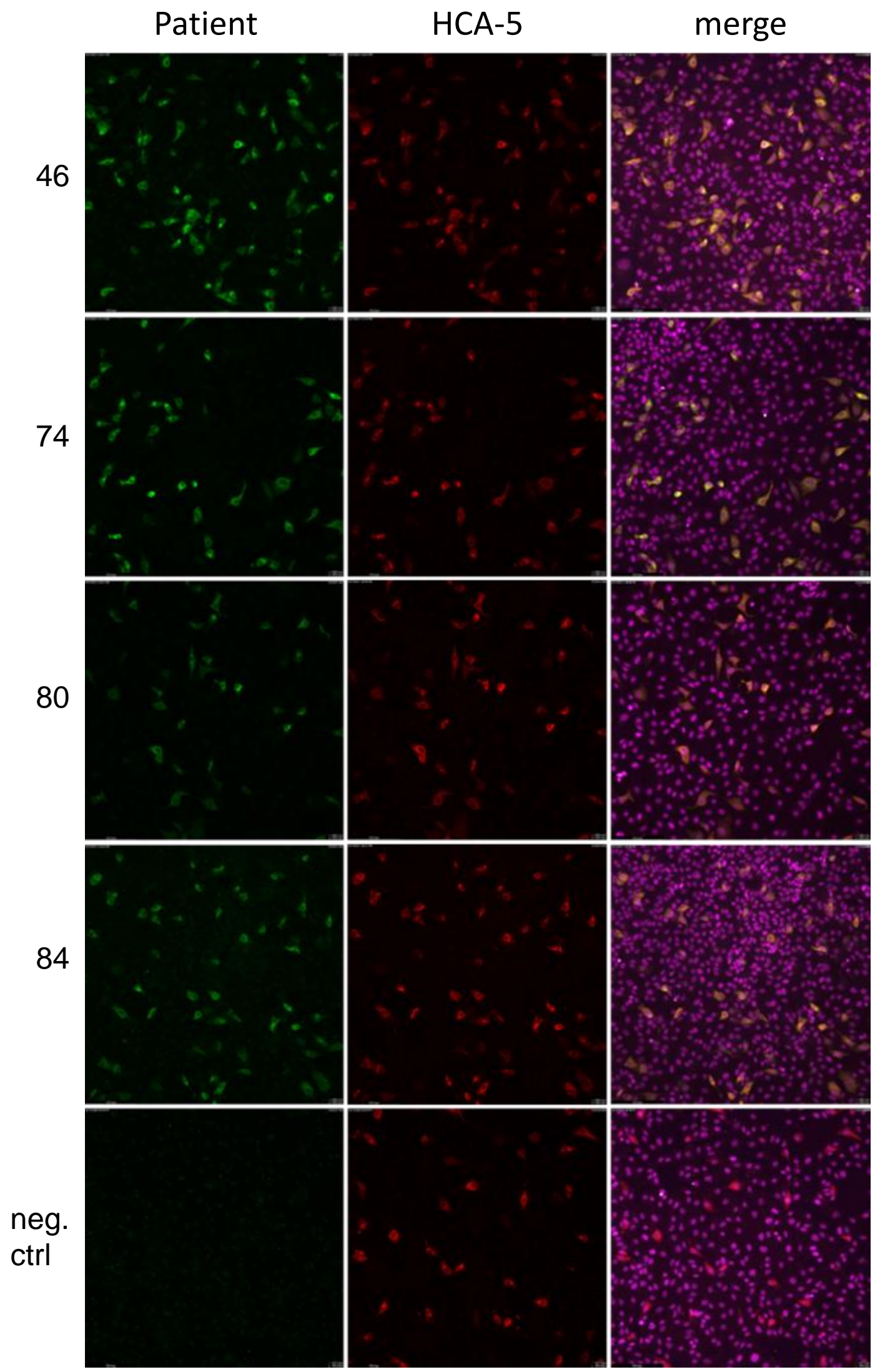


Fig. S2

A

Pat. Label ELISA IgG

\begin{tabular}{lll}
84 & 8.74 & positive \\
80 & 7.36 & positive \\
77 & 7.33 & positive \\
46 & 7.03 & positive \\
\hline 40 & 6.07 & positive \\
38 & 5.53 & positive \\
75 & 4.32 & positive \\
93 & 2.72 & positive \\
\hline 36 & 1.01 & positive \\
\hline 54 & 0.15 & negative \\
\hline
\end{tabular}

B

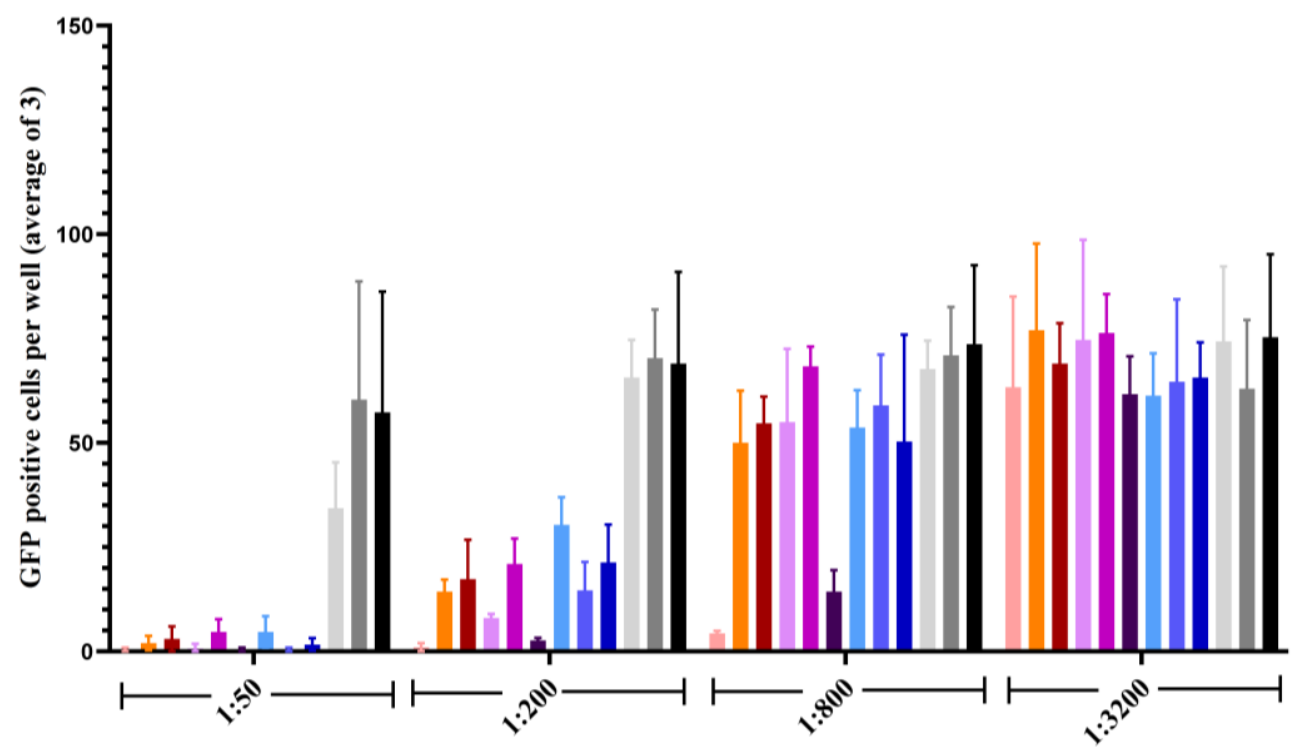

- Patient 46

- Patient 77

- Patient 80

- Patient 84

- Patient $\mathrm{X}$ borderline 36

- Patient $X$ pos. 40

- Patient $Y$ pos. 93

- Patient $Y$ pos. 38

- Patient $Z$ pos. 75

1. Patient $X$ neg. 54

- Neg Cntrl Dr.kd

- Media

C

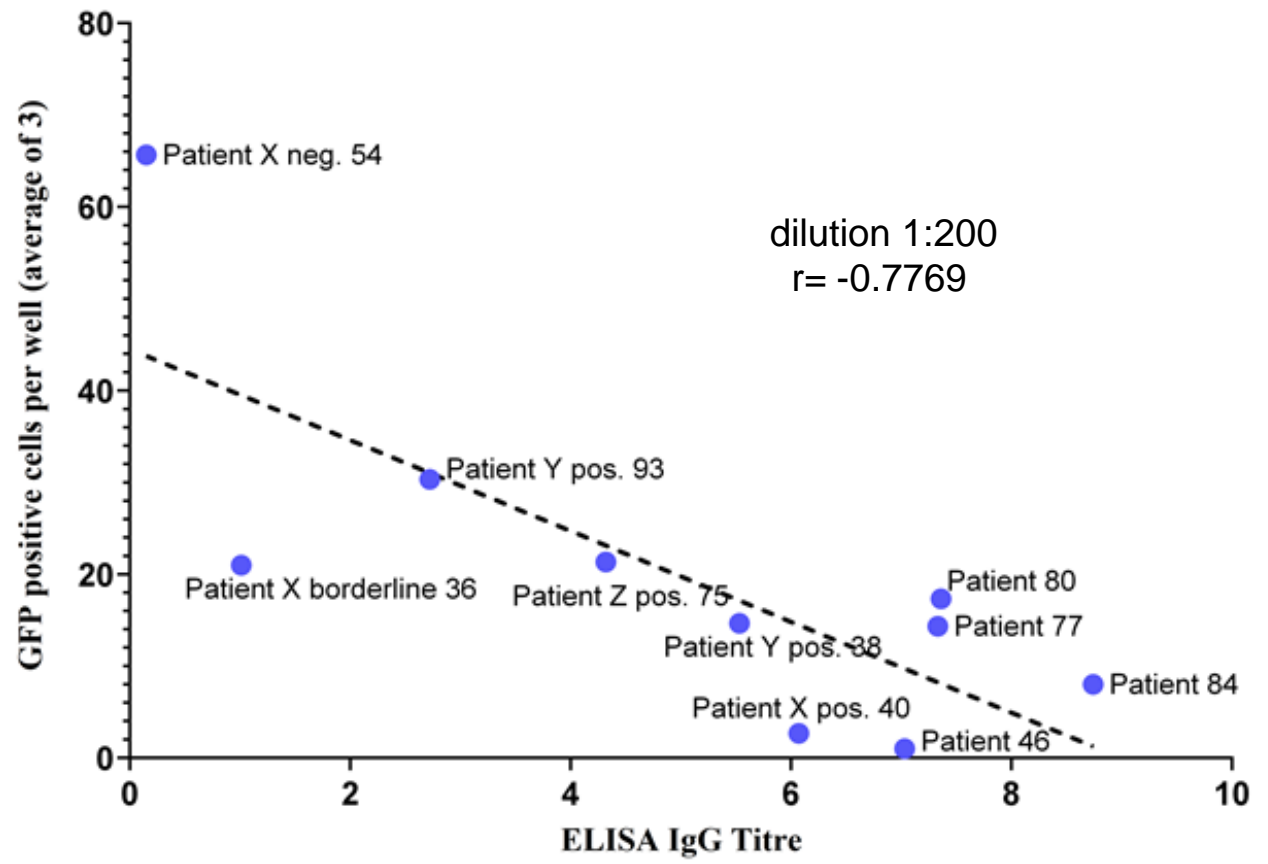

